Article

\title{
Analysis of Release Model Effect in the Transport of Fission Products Simulating the FPT3 Test Using MELCOR 2.1 and MELCOR 2.2
}

\author{
Alain Flores y Flores ${ }^{1,2, *}$, Danilo Ferretto ${ }^{1}$ (D) , Tereza Marková ${ }^{3}$ and Guido Mazzini ${ }^{1,2}$ \\ 1 National Radiation Protection Institute (SURO v.v.i.), Bartoškova 28, 14000 Praha, Czech Republic; \\ danilo.ferretto@suro.cz (D.F.); guido.mazzini@suro.cz (G.M.) \\ 2 Centre Ǩež, CV Ǩež, s. r. o., Hlavní 130, Ǩež, 25068 Husinec, Czech Republic \\ 3 Department of Nuclear Reactors, Faculty of Nuclear Sciences and Physical Engineering, \\ Czech Technical University in Prague, V Holešovičkách 2, 18000 Praha, Czech Republic; \\ tereza.markova@sujb.cz \\ * Correspondence: alain.flores@suro.cz or alain.flores@cvrez.cz; Tel.: +420-266-172-536
}

\section{check for} updates

Citation: Flores y Flores, A.; Ferretto, D.; Marková, T.; Mazzini, G. Analysis of Release Model Effect in the Transport of Fission Products Simulating the FPT3 Test Using MELCOR 2.1 and MELCOR 2.2. Sustainability 2021, 13, 7964. https:// doi.org/10.3390/su13147964

Academic Editors:

Guglielmo Lomonaco and

Changhyun Roh

Received: 25 May 2021

Accepted: 9 July 2021

Published: 16 July 2021

Publisher's Note: MDPI stays neutral with regard to jurisdictional claims in published maps and institutional affiliations.

Copyright: (c) 2021 by the authors. Licensee MDPI, Basel, Switzerland. This article is an open access article distributed under the terms and conditions of the Creative Commons Attribution (CC BY) license (https:// creativecommons.org/licenses/by/ $4.0 /)$.

\begin{abstract}
The severe accident integral codes such as Methods for Estimation of Leakages and Consequences of Releases (MELCOR) are complex tools used to simulate and analyse the progression of a severe accident from the onset of the accident up to the release from the containment. For this reason, these tools are developed in order to simulate different phenomena coupling models which can simulate simultaneously the ThermoHydraulic (TH), the physics and the chemistry. In order to evaluate the performance in the prediction of those complicated phenomena, several experimental facilities were built in Europe and all around the world. One of these facilities is the PHEBUS built by Institut de Radioprotection et de Sûrete Nucléaire (IRSN) in Cadarache. The facility reproduces the severe accident phenomena for a pressurized water reactor (PWR) on a volumetric scale of 1:5000. This paper aims to continue the assessment of the MELCOR code from version 2.1 up to version 2.2 underlying the difference in the fission product transport. The assessment of severe accident is an important step to the sustainability of the nuclear energy production in this period where the old nuclear power plants are more than the new reactors. The analyses presented in this paper focuses on models assessment with attention on the influence of $\mathrm{B}_{4} \mathrm{C}$ oxidation on the release and transport of fission products. Such phenomenon is a concern point in the nuclear industry, as was highlighted during the Fukushima Daiichi accident. Simulation of the source term is a key point to evaluate the severe accident hazard along with other safety aspects.
\end{abstract}

Keywords: PHEBUS-FPT3; MELCOR; core degradation; severe accidents; modelling

\section{Introduction}

After Fukushima Daiichi Nuclear Power Plant (NPP) accident, an increase of the risk perception of the health effects of NPPs accidents was detected [1]. The European Commission required to carry out stress tests on all NPPs placed in the European Union (EU) Member States. The conclusions of this analysis have led EU members to improve their knowledge on severe accident phenomenology to ensure the nuclear energy is a safe and sustainable energy option [2].

For sustainable use of nuclear technology for energy production, several computational tools are developed in order to design and to assess the reactor safety performance also evaluating the safety margin. Such computational tools are important as well as the component design and manufacture procedure due to their key role in maintaining the nuclear reactor in controlled safety state even in the presence of rare events. For this reason, computer codes need to be verified and assessed in comparison with data provided by real scenarios (e.g., Three Mile Island [3], Chernobyl [4] and Fukushima [5]) or through experimental facility as PHEBUS [6,7]. Although severe accidents remain the most valuable 
data for the assessment, they lack often of detailed information, limited by the designed Instrumentation and Control (I\&C) systems. For this reason, several experimental campaigns in severe accident were performed in order to get specific measurements for evaluation of the models in comparison of physics. In particular, PHEBUS Fission Products Test (FPT) 3 [8] experiment consists of one of the most complete data available for simulating the phenomena that could occur during a severe accident. The presence of the central boron carbide $\left(\mathrm{B}_{4} \mathrm{C}\right)$ control rod, provides additional information on simulation of the chemicalphysical behaviour of the fuel assemblies under severe accident for boiling water reactor (BWR) and, in particular, water-water energetic reactor (VVER) technologies. However, PHEBUS facility is designed to simulate western PWR, the presence of the boron carbide control rod in FPT3 test can provide additional phenomenology information to also for the VVER and BWR.

The VVER technology is broadly distributed in Central and Eastern Europe. In the Czech Republic there are 4 VVER-440 units located in Dukovany and two units VVER-1000 located in Temelin. In particular, the VVER-1000 units are characterised by hexagonal fuel assemblies with $\mathrm{B}_{4} \mathrm{C}$ control rod. As part of the Technical Support Organisation (TSO) activities, National Radiation Protection Institute (SURO), in collaboration with Research Centre Řež (CVR) is performing several analyses of the Czech Nuclear Power Plants (NPPs) along with the computer codes and user assessment using several different experiments. For severe accident, particular attention was given in SURO to the PHEBUS FPT3 simulation using MELCOR 2.1 and MELCOR 2.2. code versions. Such codes can be used to simulate severe accidents evaluating the scenarios, which may lead to consequences more severe than the normal design base accidents. MELCOR, specifically, is the most widely used integral code used for severe accident scenarios assessment in the Czech Republic and broadly used also around the world.

This work aims to prepare models for the assessment of the MELCOR 2.1 version $6342[9,10]$ and MELCOR 2.2 version 15,254 [11,12]) in order to understand the code capacity to simulate similar phenomena, which might occur in VVER technology during a Severe Accident (SA) scenario. Such study is a part of documentation that is intended to be presented to the State Office of Nuclear Safety (SUJB) for the code and user qualification process.

This activity focuses on developing the PHEBUS FPT-3 facility model for assessing the capabilities of the MELCOR code versions 2.2 in simulating the degradation phenomena during a SA from the TH behaviour up to the Fission Products (FPs) release in the reactor coolant system and the containment building. Particular attention is given to the $\mathrm{B}_{4} \mathrm{C}$ oxidation simplified model and how it influences core melt progression and the release model. Based on these outcomes, furthermore, the project aims to develop and assess the necessary models to simulate the progression of a severe accident and evaluating the source term during SA scenarios for a VVER-1000 and VVER-440.

The actual work done in SURO and CVR focuses on a similar approach done in FPT3 benchmark $[13,14]$, where the TH, fuel mechanic relocation, hydrogen production, gas and FPs transport behaviours are simulated in comparison with the reference data. In addition, particular attention was given to the FPs transport focusing on the release model used in MELCOR. For this reason, two different nodalizations were prepared to understand the influence of the release model on the source term in the containment vessel. One nodalization is characterised by a complete model of the facility from the active channel (fuel bundle) up to the containment vessel. The second nodalization is modelled simulating the circuit and the containment vessel, where steam, hydrogen and FPs are imposed as boundary condition from the data obtained by the experiment in Point $\mathrm{C}$ (hot leg). Particular attention was given also to the benchmark code-to-code between MELCOR 2.1 and MELCOR 2.2 highlighting the differences in the COR model changes through the analysis of the results. 


\section{Facility Description}

The PHEBUS FP programme [8] was the core of an international research cooperation via performing several in-pile experiments of the relevant phenomena, which lead to the progression of postulated severe accidents in light water reactors (LWRs). The FPT-3 experiment was chosen, because in that experiment a $\mathrm{B}_{4} \mathrm{C}$ control rod was used similar composition to the control rods used in the VVER models in Czech Republic. Although the boron carbide is a refractory material, which does not melt until the temperature is around $2800 \mathrm{~K}$ (similar to $\mathrm{UO}_{2}$ ), it can react with steam and other materials.

The conditions similar to those expected in severe accidents of a real power plant were reproduced in the PHEBUS facility [7], allowing detailed investigation of the basic phenomena that determine the release, transport, deposition and retention of FPs. These phenomena occur in the core region, in the primary circuit and in the containment and implicate a robust connection between thermal-hydraulics and chemical/physical processes defining the aerosol behaviour.

The PHEBUS facility also offers the capability to study the degradation of real core material, from the early phase of cladding oxidation and hydrogen production up to the late phase of melt progression and molten pool formation. The subsequent release of FPs and structural materials are also experimentally studied, including their physicochemical interactions, their transport in the cooling system, and their deposition in the containment. The re-volatilisation of iodine due to radiochemical effects in the water of the sump and the quantity of low-volatility FPs and transuranium elements reaching the containment are receiving a special interest, as large uncertainties related to their modelling subsist.

The following paragraphs describe each part of the facility, in particular focusing on the parts nodalized in the simulations with MELCOR code [15]. A more detailed description of the bundle, circuit and containment vessel can be founded in [14-16].

The PHEBUS test facility circuit is a mock-up (5000:1) of the primary circuit of $900 \mathrm{MWe}$ PWR plant. It is divided in four different sections $[14,17,18]$ : Test Section, Hot Leg Line, Steam Generator and Cold Leg Line. The gases and aerosols released from the experiment during the degradation phase of the fuel bundle were transported through experimental lines to the containment vessel. The experimental cell is placed in a loop crossing the central part of the PHEBUS driver core which supplies the nuclear power as is shown in the Figure 1.

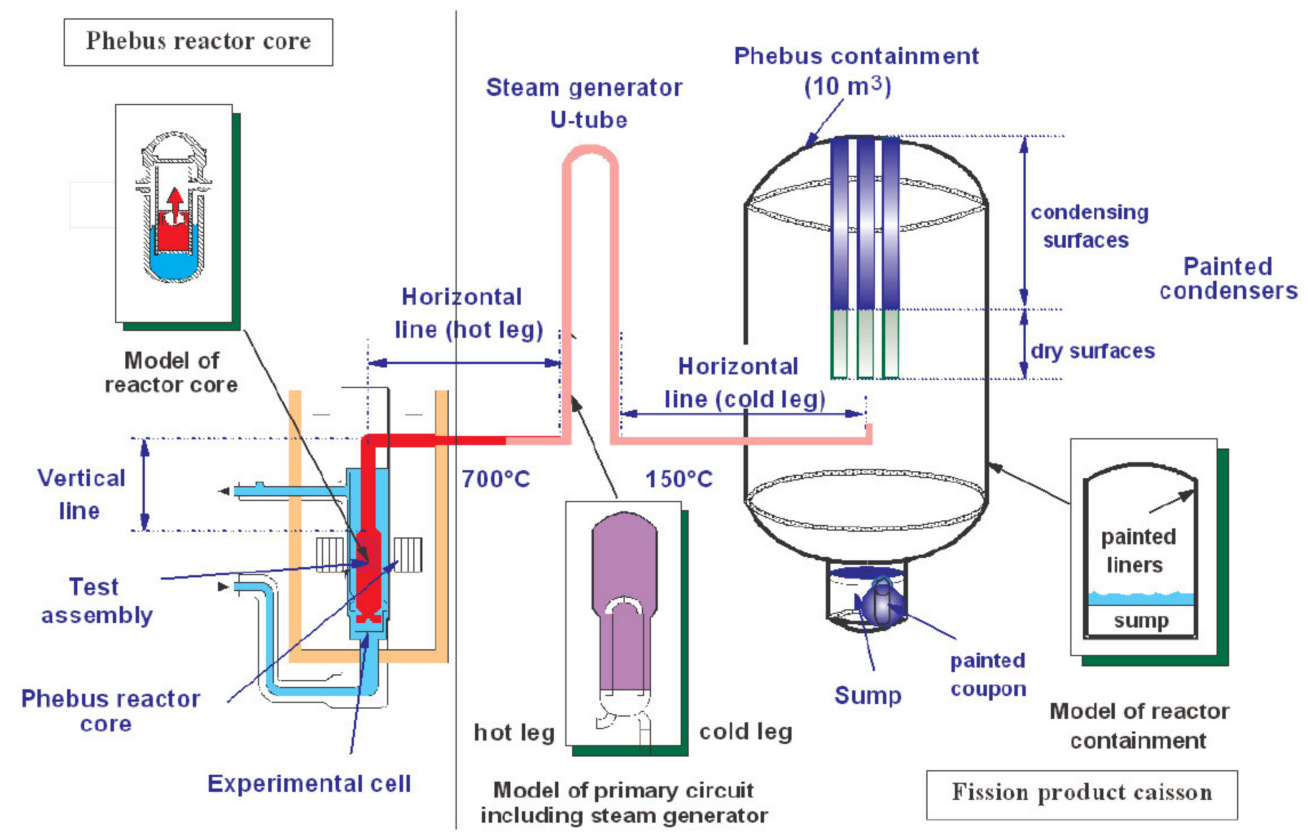

Figure 1. The PHEBUS-FP experiment facility. 
The experimental lines are composed of:

- a vertical line is located above the test bundle (vertical line, $\sim 3 \mathrm{~m}$ high, inner diameter $0.073 \mathrm{~m}$ reducing in steps to $0.048 \mathrm{~m}$ and then to $0.03 \mathrm{~m}$ ) is composed of the upper plenum and the riser. A section of the liner at the temperature controlled-part of the vertical line was manufactured of stainless steel, while Inconel 600 was used to the rest; this allows studying the differences in deposition on these materials.

- The steam generator is made of Inconel-600; ( 4 $\mathrm{m}$ high with an inner diameter of $0.02 \mathrm{~m}$ ). The U-tube outlet and the horizontal line $(4 \mathrm{~m}$ long with an inner diameter of $0.03 \mathrm{~m}$ ), simulating the conditions in the cold leg, are made of stainless steel (AISI 304L).

The containment vessel has cylindrical form ( $5 \mathrm{~m}$ height, $1.8 \mathrm{~m}$ outer diameter) the walls of the containment are made of AISI 316L grade stainless steel with $10 \mathrm{~m}^{3}$ free volume. The volumetric scale factor corresponds to the ratio between the core mass of a $900 \mathrm{MWe}$ PWR and fuel element mass of the PHEBUS core, i.e., about 5000:1 as volume scale [8]. The aim is to keep constant the concentration of the FPs constant, with respect to the 900 MWe PWR containment volume. The top dome of the containment vessel is equipped with a group of three condensers, which control the heat transfer and steam condensation, simulating the cold structures of a real reactor building.

The lower part of each condenser is kept dry by heaters and it contains equipment to collect the condensate. When the collection device is full, the condensate is drained into the sump. The surface of the condensers is covered with epoxy paint, which traps the iodine molecule, hence, for this reason, the iodine organic compounds could be developed. A recent study [19] showed that the iodine speciation, mainly triggered by the thermalhydraulics condition and by the radiolysis, is more accurate in MELCOR then others codes. The vessel walls are slightly superheated to avoid steam condensation and aerosol contamination. At the lower part of the vessel closed by an elliptic lid, the sump is located $\left(0.1 \mathrm{~m}^{3}\right.$ volume and $0.584 \mathrm{~m}$ of diameter). The water in the sump can be recirculated to prevent an excessive increase of temperature. A spray system can be activated to wash the aerosols from the bottom of the vessel to the sump.

\section{Description of the FPT 3 Experiment}

The first test FPT0 was performed using trace-irradiated fuel in a fresh matrix $(\sim 0 \mathrm{GWd} / \mathrm{tU})$, while the other tests were irradiated at different burnups ( $23 \mathrm{GWd} / \mathrm{tU}$ for FPT1 [17], $\sim 32 \mathrm{GWd} / \mathrm{tU}$ for FPT2 [18] and $24.5 \mathrm{GWd} / \mathrm{tU}$ for FPT3 [14]). The FPT1 and FPT2 tests bundles contain fuel rods previously irradiated in the Belgian BR3 reactor, where they obtained the rod average burn as indicated in the Table 1. Two fresh instrumented fuel rods were also introduced into the bundle as well as $\mathrm{Ag}$, In, $\mathrm{Cd}$ (AIC) absorber control rod (containing $80 \mathrm{wt} . \%$ silver, $15 \mathrm{wt} . \%$ indium and $5 \mathrm{wt} . \%$ cadmium). In the case of FPT3 the control rod is composed of $\mathrm{B}_{4} \mathrm{C}$.

Table 1. Summary of PHEBUS test cases.

\begin{tabular}{cccccc}
\hline Test & $\begin{array}{c}\text { Number of Fresh }+ \\
\text { Irradiated + Absorber Rods }\end{array}$ & $\begin{array}{c}\text { Fuel Burnup } \\
\text { (GWd/tU) }\end{array}$ & Bundle Flow & Containment & Date of Test \\
\hline FPT0 & $20+0+1$ SIC * & Trace & Steam rich & pH5 non evaporating sump & 2 December 1993 \\
\hline FPT1 & $2+18+1$ SIC & $\sim 23$ & Steam rich & pH5 non evaporating sump & 26 July 1996 \\
\hline FPT2 & $2+18+1$ SIC & $\sim 32$ & $\begin{array}{c}\text { Steam poor with } \\
\text { boric acid }\end{array}$ & pH9 evaporating sump & 12 October 2000 \\
\hline FPT3 & $2+18+1 B_{4}$ C & $\sim 24$ & Steam poor & pH5 evaporating sump & 18 November 2004 \\
\hline FPT4 & $\begin{array}{c}\text { Pre-formed debris bed; no } \\
\text { absorber or metallic Zry }\end{array}$ & $\sim 38$ & Steam + H2 & & 22 July 1999 \\
\hline
\end{tabular}

*SIC—silver/indium/cadmium. 
Each experiment consisted of a re-irradiation period of approximately 7-9 days at a mean power of $205 \mathrm{~kW}$ (FPT1), $232 \mathrm{~kW}$ (FPT2) and $220 \mathrm{~kW}$ (FPT3), so as to generate the short-lived FP inventory. This pre-conditioning phase was followed by a $5 \mathrm{~h}$ transient, during which steam at a pressure of $\sim 0.2 \mathrm{MPa}$ was injected into the bundle with a flow rate of $0.5 \mathrm{~g} / \mathrm{s}$ constant for FPT2 [18] and FPT3 [14], to observe steam starvation phenomena when the reduced steam flow rate is used to generate the respective mass of hydrogen.

Meanwhile, at the beginning of the test, the bundle power was increased starting from 0 , up to $32.8 \mathrm{~kW}$ for FPT3 [14]. The power generated within the fuel rods heated up the test bundle leading to the bursting of the cladding, degradation of the control rod and relocation of the absorber material. Consequently, cladding oxidation and hydrogen generation, melt relocation and accumulation, and release of FPs from bundle, structure and control rod materials take place. In the FPT3 the control rod is composed by $\mathrm{B}_{4} \mathrm{C}$ also two fresh instrumented fuel rods were installed into the bundle.

The temperature evolution started as the measured cladding temperature exceeded $1840 \mathrm{~K}$ and lasted for about $5 \mathrm{~min}$ in the upper part of the bundle. The temperature peak reached $2490 \mathrm{~K}$ at an elevation of $700 \mathrm{~mm}$. The maximum heating rate was $\sim 285 \mathrm{~K} / \mathrm{s}$ at an elevation of $800 \mathrm{~mm}$. The total mass of hydrogen produced during the FPT3 was $120 \mathrm{~g}$.

A second rapid heat up at the bottom of the shroud, associated with a second fuel relocation, was detected $\sim 2 \mathrm{~min}$ before the end of this phase of the test. This second temperature peak in the lower part of the shroud triggered reactor shutdown and the end of the "bundle degradation" phase of the test. An important amount of FPs-more than $80 \%$ of the initial bundle inventory of those most volatile-was released in addition to some structural material from the spacer grids, bundle and control rod during the melting progression. Releases were transported by the steam flow, through the experimental line to the containment vessel. The transient was completed by core shutdown and the cooling of the bundle with steam for $\sim 26 \mathrm{~min}$. Detailed timing of experimental phases and results can be seen in the Section 6.

\section{MELCOR Code Description}

The MELCOR code is fully integrated, system computer code which allows to model the progression of severe accidents in light water nuclear power plants. This code is developed by Sandia National Laboratories for the needs of the United States-Nuclear Regulatory Commission (US-NRC). MELCOR is used to perform sensitivity and uncertainty analyses in different applications [20].

The severe accident simulations include a wide-range of phenomena, including thermal-hydraulic feedback in the reactor coolant system and containment; the core overheating, its degradations and the gradual relocation in the bottom of the vessel; the hydrogen production and the fission products issue [20].

Thermal-hydraulic behaviour of water and gases in MELCOR are modelled by Control Volumes (CVs) and flow paths packages. The CVs include so-called hydrodynamic materials (associated with their energy), such as water, vapour, fog and non-condensable gases. Due to the stratification phenomena, each CV is divided in pool, placed into the bottom, and atmosphere in the upper part. The flow paths are the connections between the CVs through which the hydrodynamic materials can flow. Since the material cannot reside into the flow paths, there is no heat and mass transfer between hydrodynamic materials [20].

The RadioNuclide (RN) package models the behaviour of fission product aerosols and vapours and other trace species, including release from fuel and debris, aerosol dynamics with vapour condensation and re-vaporisation, deposition on structure surfaces, transport through flow paths, and removal by engineered safety features.

Boundary conditions for the various models are obtained from other MELCOR packages: fluid conditions are obtained from the Control Volume Hydrodynamics (CVH) package, fuel and debris temperatures are obtained from the Core (COR) and Cavity (CAV) packages, and structure surface temperatures are obtained from the Heat Structures (HS) package. Likewise, advection of radionuclides between control volumes is done using CVs 
flows and wash-off of radionuclides deposited on heat structures, is determined from the drainage of water films calculated by the HS package. The RN package determines decay heat power for current radionuclide inventories from the Decay Heat $(\mathrm{DCH})$ package when requested by each of these packages [21].

However, the two codes version present the similar core modelling approach including the phenomenology of molten relocation and transport several changes are detectable in the default values of the sensitivity coefficients as minimum porosity for flow (COR SC1505(1)) [22] and SC1003 which have specific value also for the aluminium cladding simulation [12]. The main change in the modified sensitivity coefficient values are addressed by the outcome of the material properties occurred in Fukushima Daicchi SA [23,24]

\section{PHEBUS Facility Models}

The activity focuses on developing the PHEBUS FPT-3 facility model for assessing the capabilities of the MELCOR code version 2.2 in simulating the degradation phenomena during a SA from the $\mathrm{TH}$ behaviour up to the fission products release in the reactor coolant system and the containment building, which would occur in VVER technology during a SA scenario. Particular attention is given to the boron carbide oxidation simplified model and how it influences the core melt progression and the release model. In addition, the FP transport was modelled focusing on the influence of the active channel in the transportation and deposition of the radionuclides through the test circuit. For this reason, two different nodalizations were prepared in order to understand the influence of the release model on the source term in the containment vessel. One nodalization is characterised by a complete model of the facility from the active channel (fuel bundle) up to the containment vessel. The second nodalization is modelled simulating the circuit and the containment vessel, where steam, hydrogen and FPs are imposed as boundary condition from the data obtained by the experiment in the Point $C$ (hot leg). In addition, those two nodalizations are modelling and simulating in two different versions of the MELCOR code (2.1 and 2.2): this benchmark code-to-code is used as additional assessment for the MELCOR 2.2 code in parallel with the comparison of the results with the PHEBUS experiment

\subsection{Nodalization Including the Fuel Bundle}

The PHEBUS-FPT3 nodalization, originally prepared in MELCOR 1.8.5 and updated to the version 1.8.6 was adapted and converted into MELCOR 2.1 and MELCOR 2.2 including a complete review of the boundary conditions and activated model in order to assess the congruency with the original model. Such nodalization was originally developed as part of the work done for the PHEBUS-FP3 benchmark $[14,15]$.

The Figure 2 refers to the schematic view of the nodalizations used in the MELCOR simulation. The nodalizations were based on the specification of FPT3 benchmark done in the framework of Severe Accident Research NETwork (SARNET) 2 research program. The MELCOR COR package consist of $2 \mathrm{CV}$ s elements and the whole fuel bundles is associated to $22 \mathrm{COR}$ nodes, divided in 2 rings and 11 axial nodes as shown in Figure 3. In addition, these nodalizations have been set up on the basis of International Standard Problem 46 (ISP-46) specification [7], which simulates the FPT1 experimental test.

A particular attention was given to the boundary and initial conditions imposed to simulate the evolution of the first part of the FPT3 test. These conditions are set up in similar way with PHEBUS-FP3 benchmark [14] and the FPT3 Final Report [13,25].

The circuit is nodalized as shown in Figure 4: MELCOR nodalization is characterised by the Hot Leg divided into five CVs, while the Cold Leg is characterised by only $2 \mathrm{CVs}$. The reason is based on the transport of the FPs where in the Hot Leg there is a higher deposition for inertia than in the Cold Leg. This nodalization was set up in accordance with the benchmark specifications for reference calculations and based on recent study [16] which demonstrated the need of a sufficient number of volumes for a correct prediction of the coupling between the containment thermal-hydraulics transient and the aerosol behaviour. 
For the containment volume nodalization, it consists in $5 \mathrm{CVs}$ connected by several flow paths and completed with the heat structures simulating the condensators (dry + wet parts) and the containment vessel shell. The simplified model differs from the benchmark specification (see Figure 5) in order to separate the effect of the lower pool from the whole containment free volume. The rest of the pattern is to evidence the natural circulation between the condenser and the rest of the containment.

\subsection{Nodalization without the Fuel Bundle}

A similar nodalization as in the previous Section 5.1 was performed but removing the active channel section and directly implementing the experimental results for steam flow mass, hydrogen, and aerosols source rate, as were measured at that point. This model is applied to eliminate the uncertainties related to aerosol deposition along the test circuit (see Figure 6).

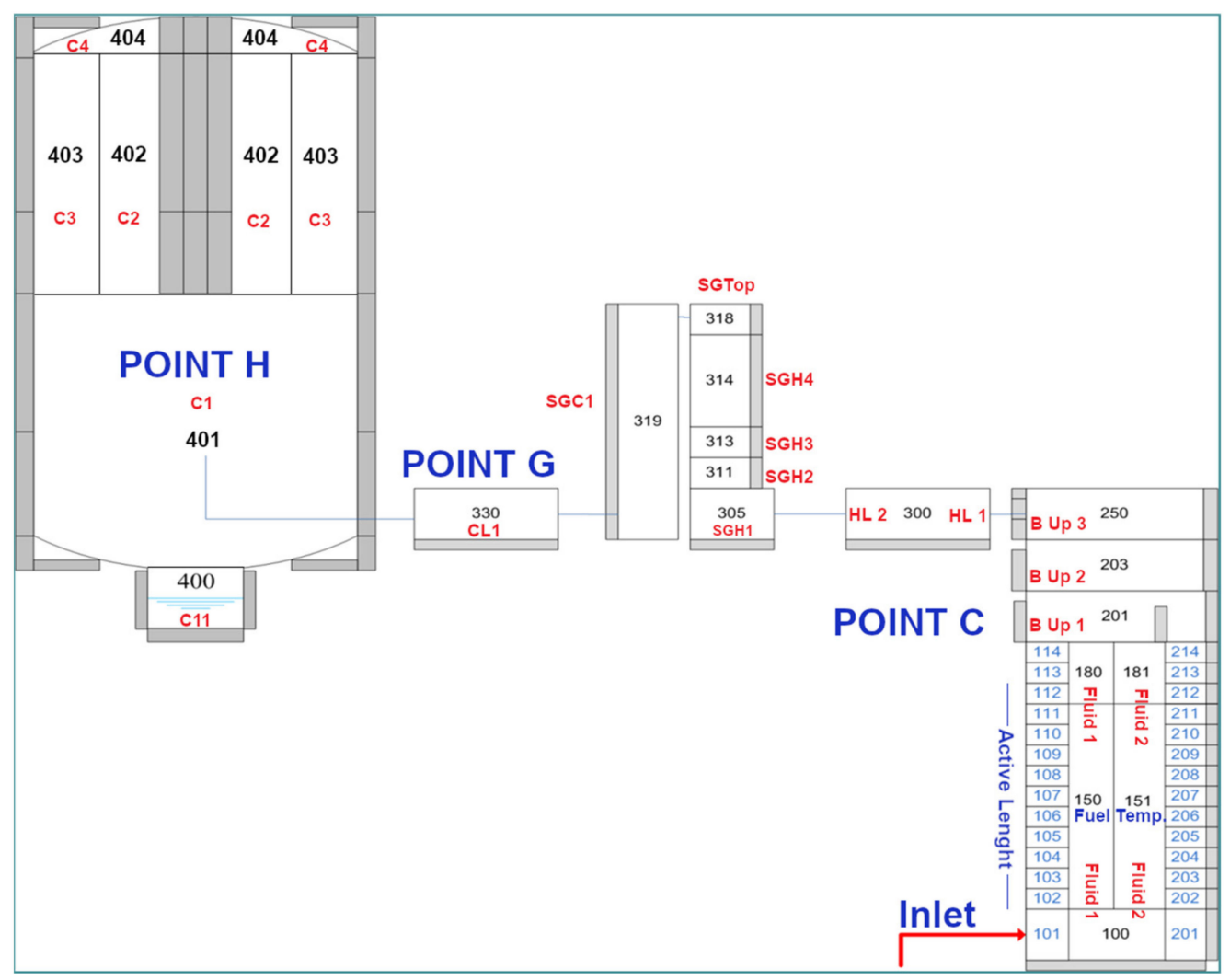

Figure 2. FPT3 Nodalizations [15]. 

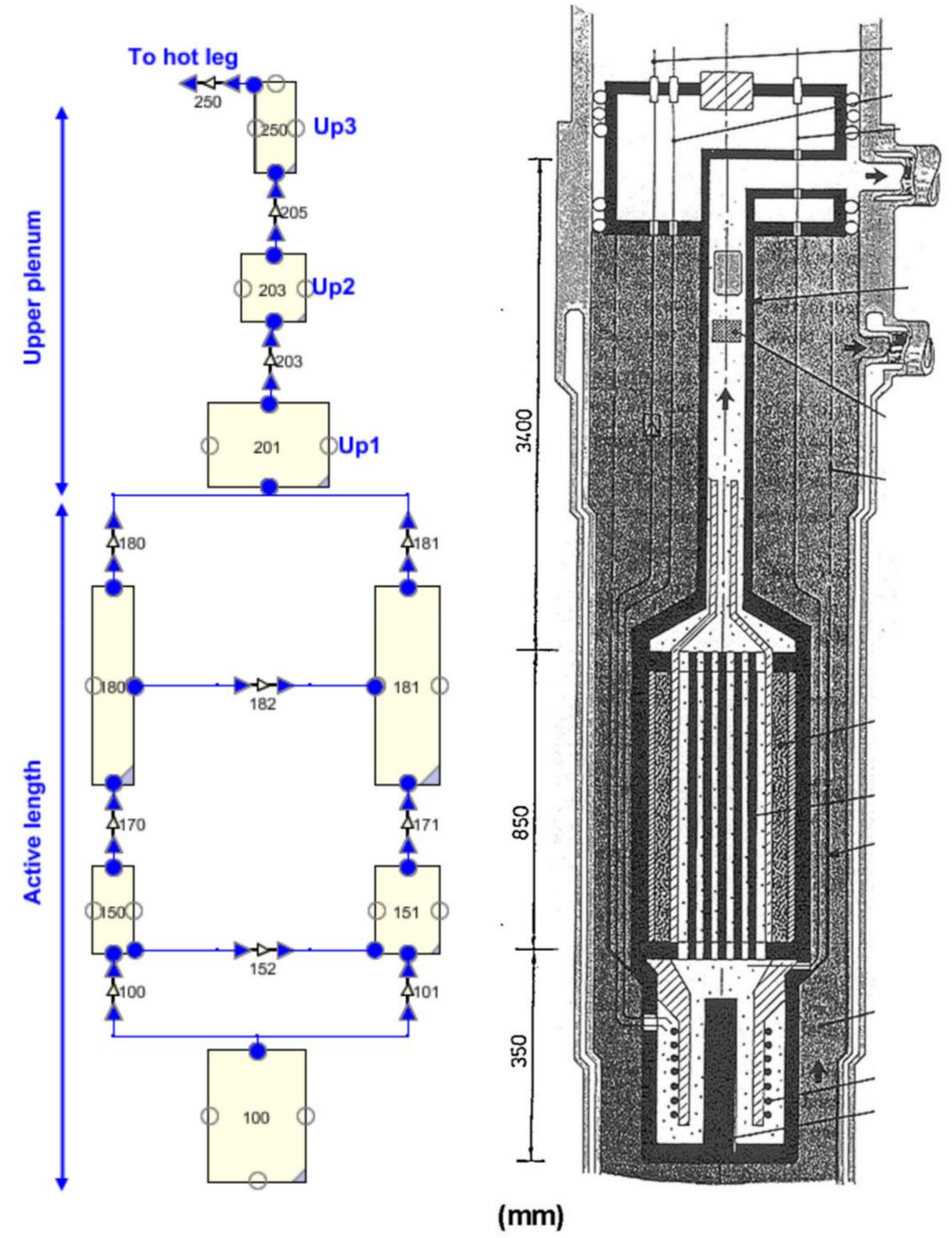

Figure 3. Bundle detailed nodalization vs. the original sketch.
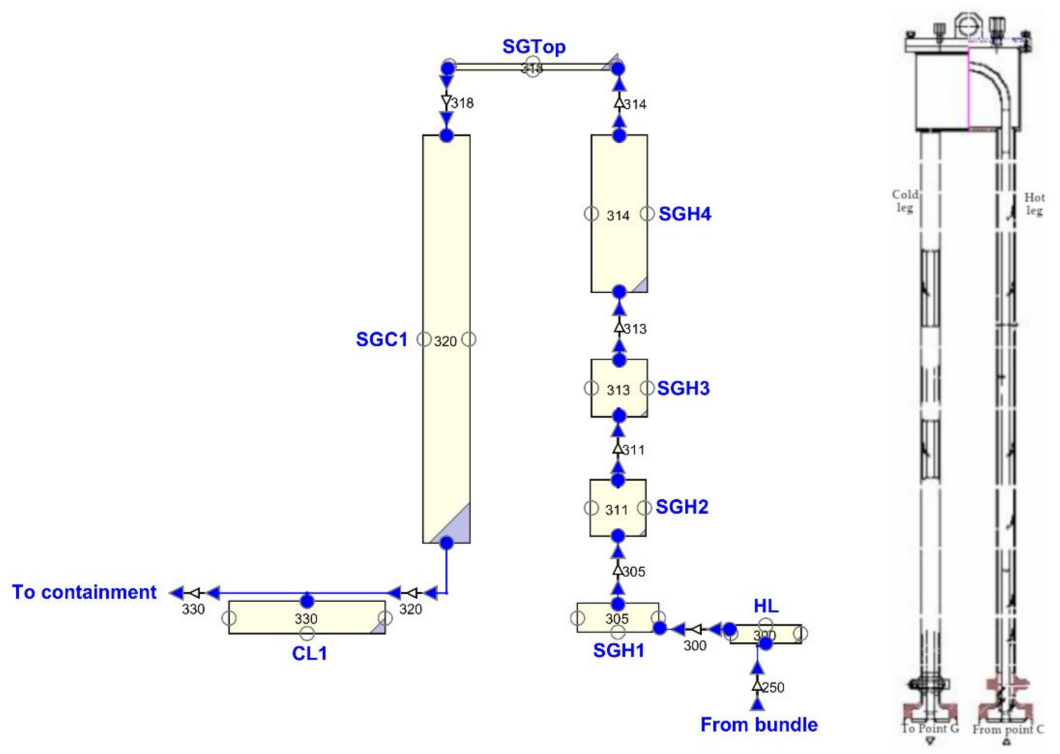

Figure 4. Circuit detailed nodalization vs. the original sketch. 

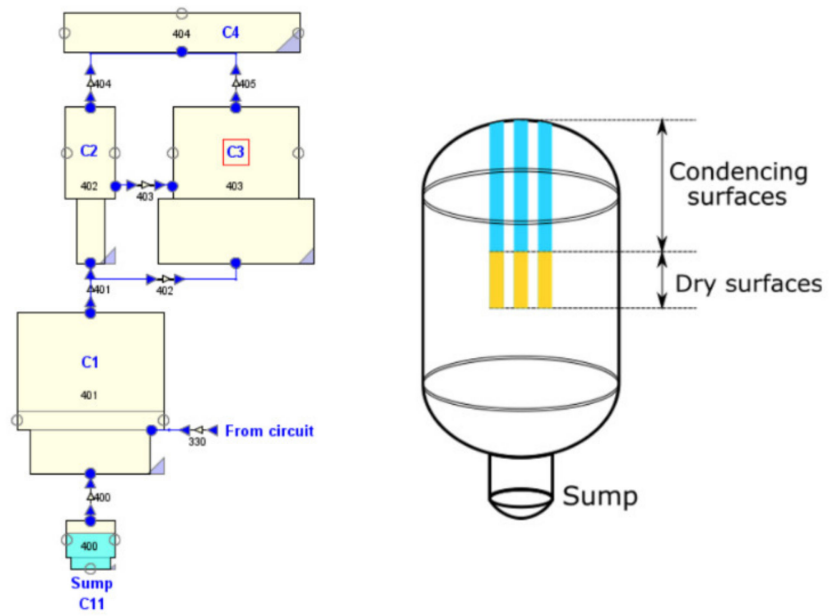

Figure 5. Containment detailed nodalization vs. the original sketch.

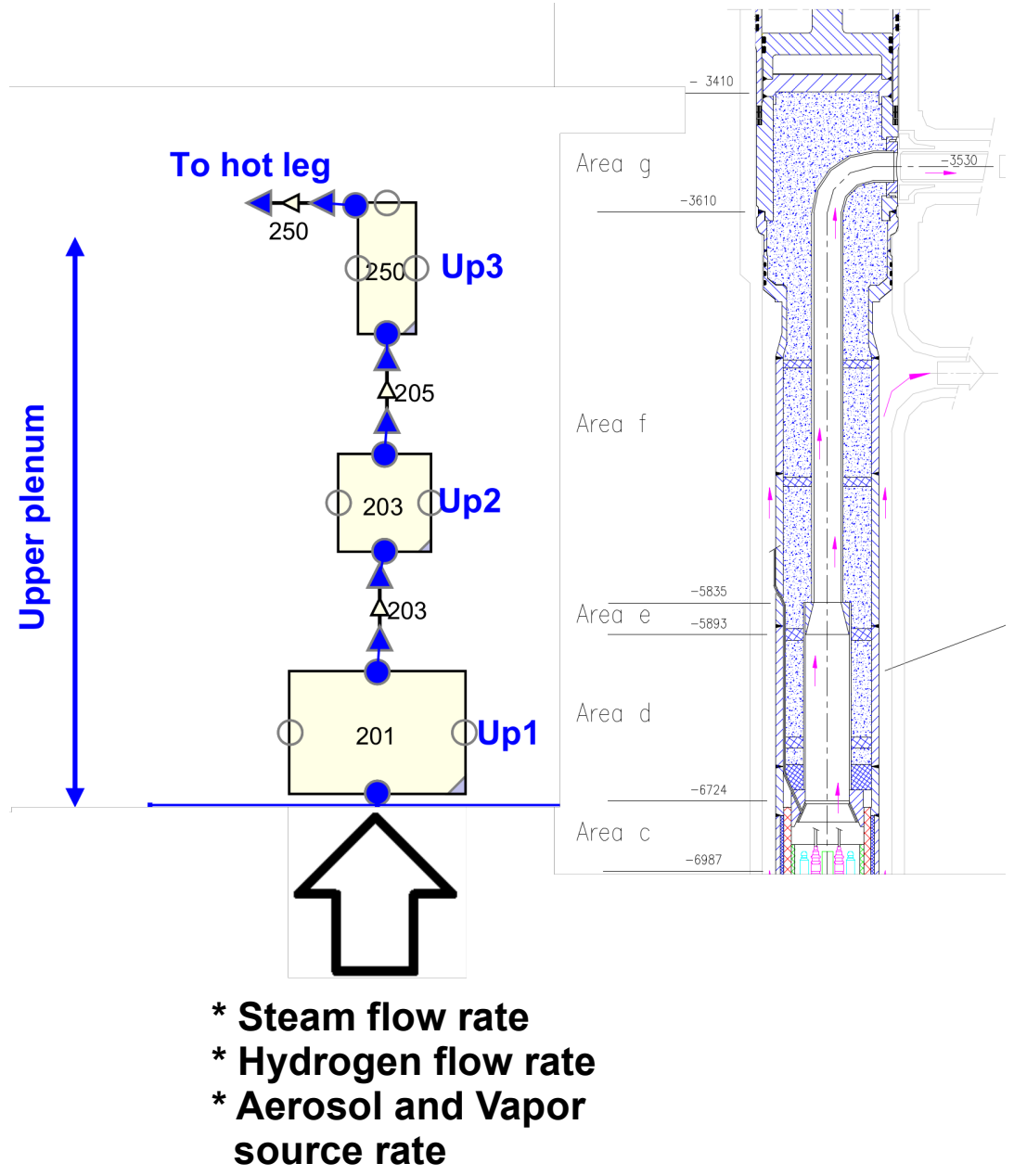

Figure 6. Nodalization without the fuel bundle.

\section{Results}

As was mentioned in the previous section, two models were developed, one considering the active channel and the other without the active channel. The objective of this double nodalization is to understand the influence of the core structures in the deposition and transport of radionuclides through the circuit. In this section the results are presented and analysed. 


\subsection{Simulation Considering the Active Channel}

\subsubsection{Thermohydraulic Behaviour}

The test boundary conditions in the pressurised water loop, in the bundle and in the experimental circuit at the transient start-up are given in Tables 2 and 3.

Table 2. Test boundary conditions in the pressurised water loop and the bundle at the transient start up.

\begin{tabular}{ccc}
\hline Fluid & Water & Pure Steam \\
\hline Cold leg pressure & About $2.7 \mathrm{MPa}$ & About $0.2 \mathrm{MPa}$ \\
Temperature & About $438 \mathrm{~K}$ & About $438.15 \mathrm{~K}$ \\
Mass flow rate & About $36 \mathrm{t} / \mathrm{h}$ & About $0.5 \mathrm{~g} / \mathrm{s}$ \\
\hline
\end{tabular}

Table 3. Test boundary conditions in the experimental circuits at the transient start-up.

$\begin{array}{cc}\text { Main FP line hot leg } & 973 \mathrm{~K} \\ \text { Stam generator wall } & 423 \mathrm{~K} \\ \text { Main FP line cold leg } & 423 \mathrm{~K} \\ \text { Containment walls } & 383 \mathrm{~K} \\ \text { Sump } & 363 \mathrm{~K} \\ \text { Condenser wet part } & 363 \mathrm{~K} \\ \text { Condenser dry part } & 393 \mathrm{~K} \\ \text { Containment pressure } & \text { About } 0.2 \mathrm{MPa}\end{array}$

All through the experiment, the steam flow rate was about $0.5 \mathrm{~g} / \mathrm{s}$. The degradation phase began at time origin $t=0 \mathrm{~s}$ : the power increase from the reactor criticality via moving four control rods to $\sim 490 \mathrm{~mm}$ level and it was terminated in two steps: prior by reactor shutdown at $\mathrm{t}=17,370 \mathrm{~s}(4.825 \mathrm{~h})$, followed by a cooling phase which ended when the steam injection was stopped at $\mathrm{t}=22,050 \mathrm{~s}(6.125 \mathrm{~h})$. The bundle degradation phase was divided into seven power sequences (at a constant steam injection rate about $0.5 \mathrm{~g} / \mathrm{s}$ ):

- A thermal calibration period, consisting of power plateaus P1 and P2 $(t=360-7920 \mathrm{~s})$, to check both the instrumentation and the thermal behaviour of the bundle (correlating bundle-temperature and driver-core-power measurements, shroud heat losses). As expected in the protocol, fuel cladding failure (hence, the first-moderate-fission product release, mainly for the noble gases) occurred during this step;

- A pre-oxidation phase, extending over the power ramp from plateau P2 to plateau P3 ( $t=7920-8640 \mathrm{~s})$, was performed to start the bundle heat-up and the Zircaloy cladding oxidation;

- Power plateau P3 $(t=8640-9000 \mathrm{~s})$ to correlate bundle temperature and driver core power measurements before the oxidation runaway;

- The oxidation phase, consisting of the power ramp from plateau P3 to plateau P4 $(t=9000-11,100 \mathrm{~s})$, when the control rod rupture is assumed to occur, followed by a transient Zircaloy cladding oxidation runaway. Both events are indeed detected by various measurements. Due to the moderate steam injection rate $\left(\sim 0.5 \mathrm{~g} \cdot \mathrm{s}^{-1}\right.$, as in FPT2), the oxidation actually peaked as a high hydrogen concentration phase with almost pure reducing conditions obtained in the upper part of the bundle over a period of $\sim 7 \mathrm{~min}$;

- Power plateau P4 $(\mathrm{t}=11,100-15,420 \mathrm{~s})$ to correlate bundle temperature and shroud temperature measurements before the failure of the instrumentation in the bundle expected in the subsequent power ramp;

- A final heat-up phase, extending over the rest of the power ramp ( $t=15,420-17,370 \mathrm{~s})$, to produce about $1 \mathrm{~kg}$ fuel relocation, accompanied by a large release of fission products, fuel element and structure materials relocation;

- A cooling phase, following the reactor shutdown $(t=17,370 \mathrm{~s})$ terminated the fuel degradation phase by the end of the steam injection $(t=22,050 \mathrm{~s})$.

The Figure 7 shows the described phases of the FPT3 experiment. Thermocouples (TCW) and ultrasonic temperature sensor were used to measure the temperature (TCW12 
at $500 \mathrm{~mm}$, uts 1.5 at $544 \mathrm{~mm}$ and uts 1.4 at $468 \mathrm{~mm}$ ). The results of the simulations for the fuel temperature at $0.485 \mathrm{~m}$ (TFU 106) and $0.528 \mathrm{~m}$ (TFU 107) obtained in the MELCOR code versions 2.1 and 2.2 are compared with the thermocouples measured temperatures at $0.468 \mathrm{~m}, 0.500 \mathrm{~m}$ and $0.544 \mathrm{~m}$. The MELCOR version 2.1 and 2.2 results follow the pattern of the thermocouples temperature at the same localisation. However, MELCOR overestimates the temperature increase in comparison with the experiment in particular in the later phase. For the MELCOR version 2.2, it can be observed the temperature fall in the results indicating the complete relocation of the fuel from the element COR 106 and COR 107 to the lower levels at around 12,500 s and 15,000 s indicating a significant core degradation. While MELCOR 2.1 seems to predict mitigatory progression during the early phase in vessel phenomena.

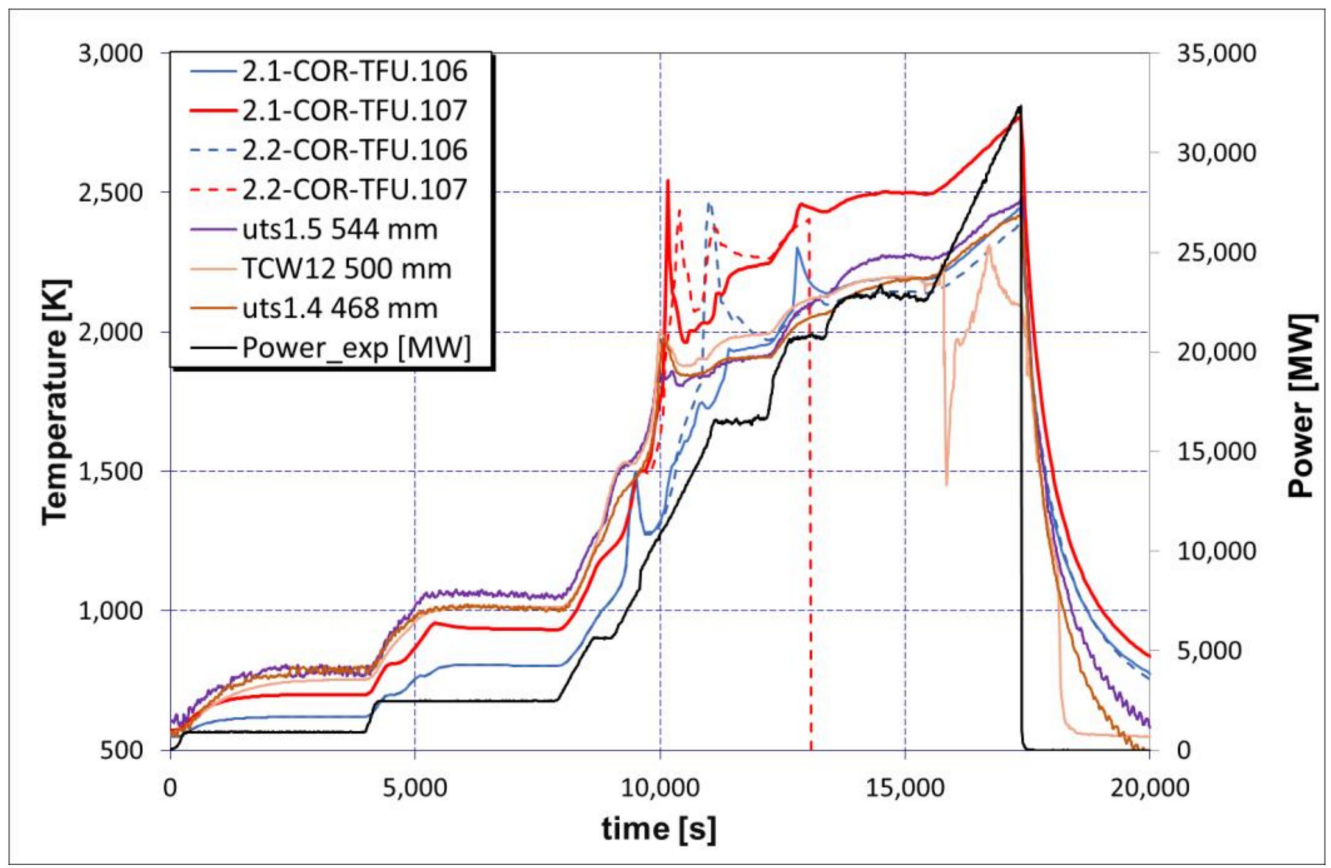

Figure 7. Fuel temperature between $0.45 \mathrm{~m}$ and $0.50 \mathrm{~m}$ of active length.

Both codes underestimate the pressure trends in the Point $C$ (Figure 8) for all the transients indicating a limitation in the heat transfer processes. As shown in Figure 8, the steam and the gas released and passed through the core and the circuit generates a significant difference with the experimental results. Indeed, similar trend is underlined also in Figure 9, where for the first 10,000 s the temperature was significantly lower indicating also a different equilibrium between the heat losses in the controlled temperature pipes with the heat generated and taken by the fluid.

Temperatures measured in the upper plenum and vertical line during the degradation phase of the experiment are shown in Figure 9. Thermocouple TCK 54 is placed at level $3567 \mathrm{~mm}$ referred to the bottom of the fissile column (BFC), TCK52 and TCK53 are both placed at level $1795 \mathrm{~mm}$ while TCK50 and TCK51 are placed at level $1340 \mathrm{~mm}$. TCK53, which measured the temperature fluid in the upper part of the upper plenum, shows clearly problems in managing temperature at the outlet of this section. On the other hand, the wall temperature measurement TCK52 follows the desired temperature of $700{ }^{\circ} \mathrm{C}$ more closely [25]. 


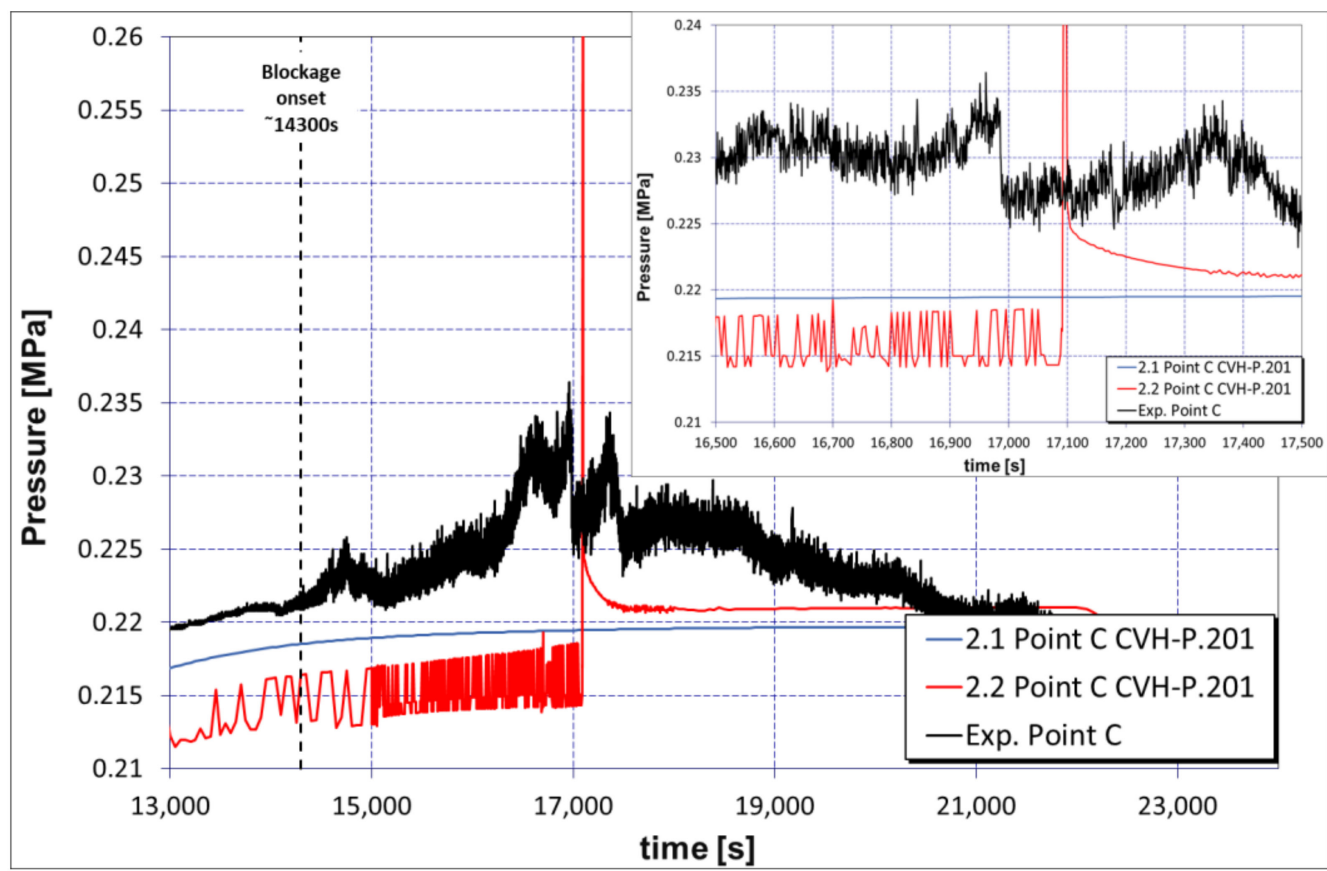

Figure 8. Pressure in Point C (hot leg) of the FPT3 facility.

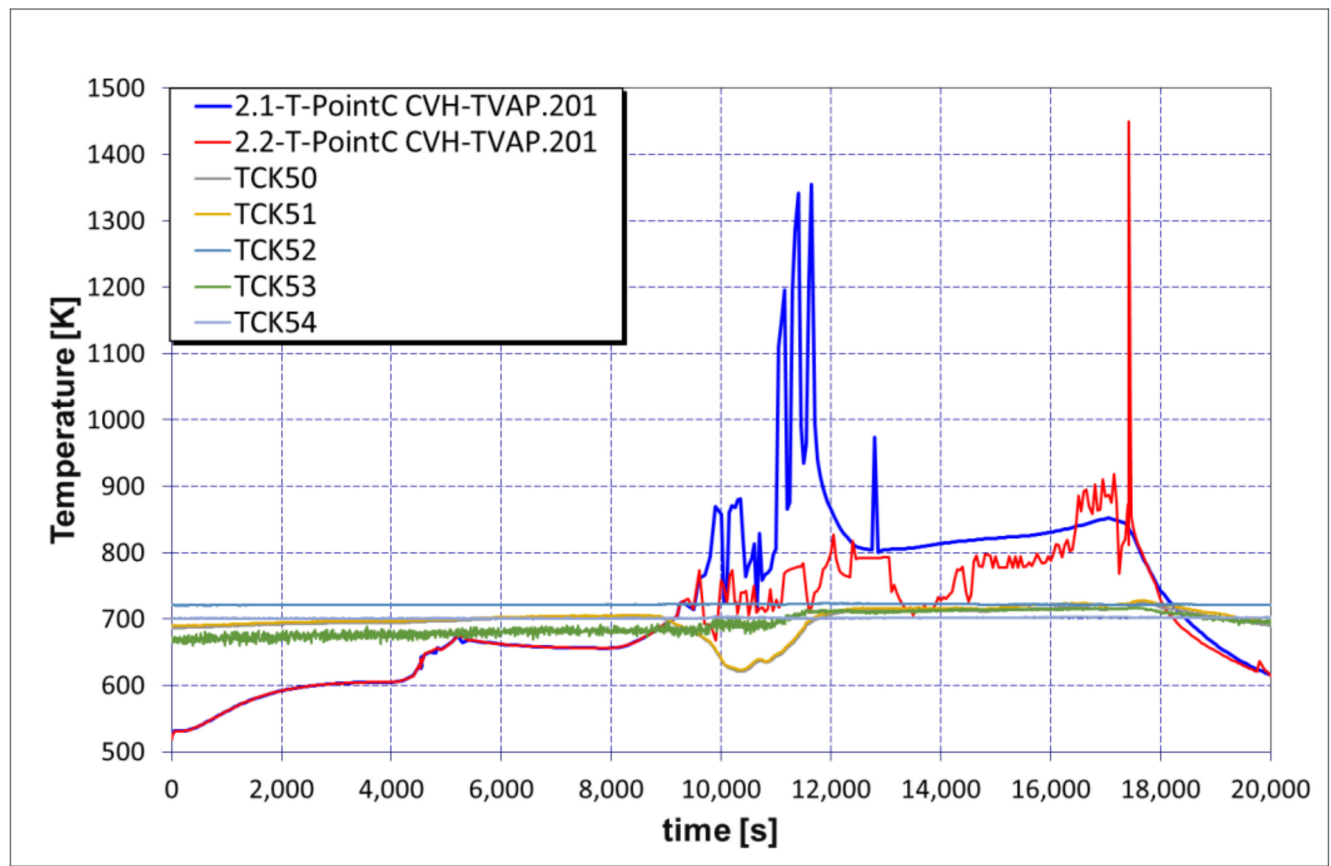

Figure 9. Fluid temperature-Point C.

After 10,000 s, the degradation process including the heat generated by the runaway reaction models (in particular the $\mathrm{B}_{4} \mathrm{C}$ oxidation) are determined to increase the temperature above the experiment underlining a parametric behaviour from the oxidation models. Moreover, this behaviour is showed in a similar shape in the hydrogen production presented in Section 6.1.2.

Such differences in the circuit are also highlighted in the Figures 10-12, where the containment behaviour is represented. In particular, in Figure 12 the atmosphere temperature has a minimum around $4000 \mathrm{~s}$ due to the start of the hydrogen production model evidencing a cooling down due to the gas expansion. Such behaviour also affects the rela- 
tive humidity as shown in Figure 13. The relative humidity presented in the containment vessel proves a slight overestimation of experimental results for the first 10,000 s while it is underestimate in the second part due to the control volume path and steam starvation that annihilate the steam due to the reactions.

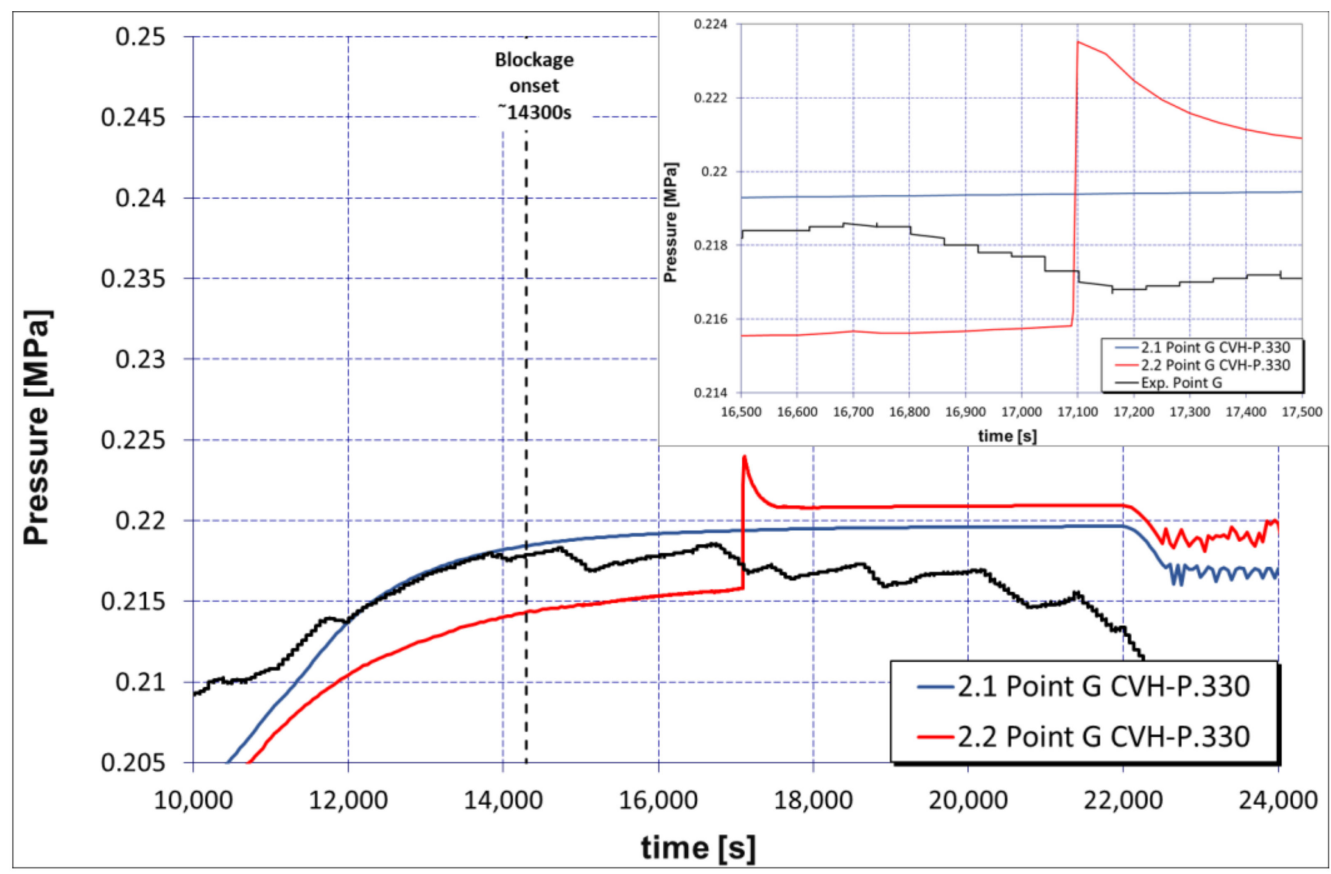

Figure 10. Pressure in Point G (cold leg) of the FPT3 facility.

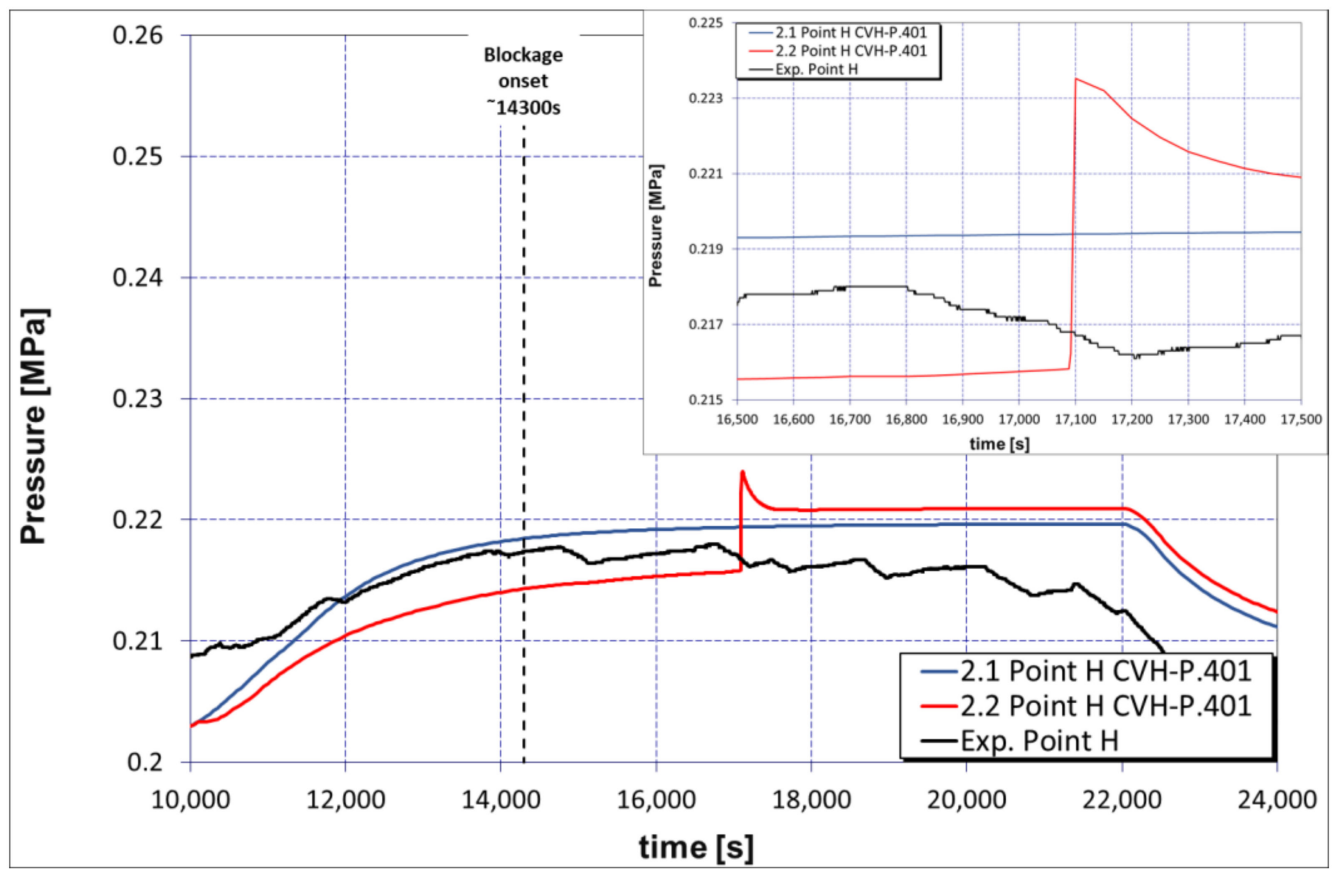

Figure 11. Pressure in Point $\mathrm{H}$ (containment vessel) of the FPT3 facility. 


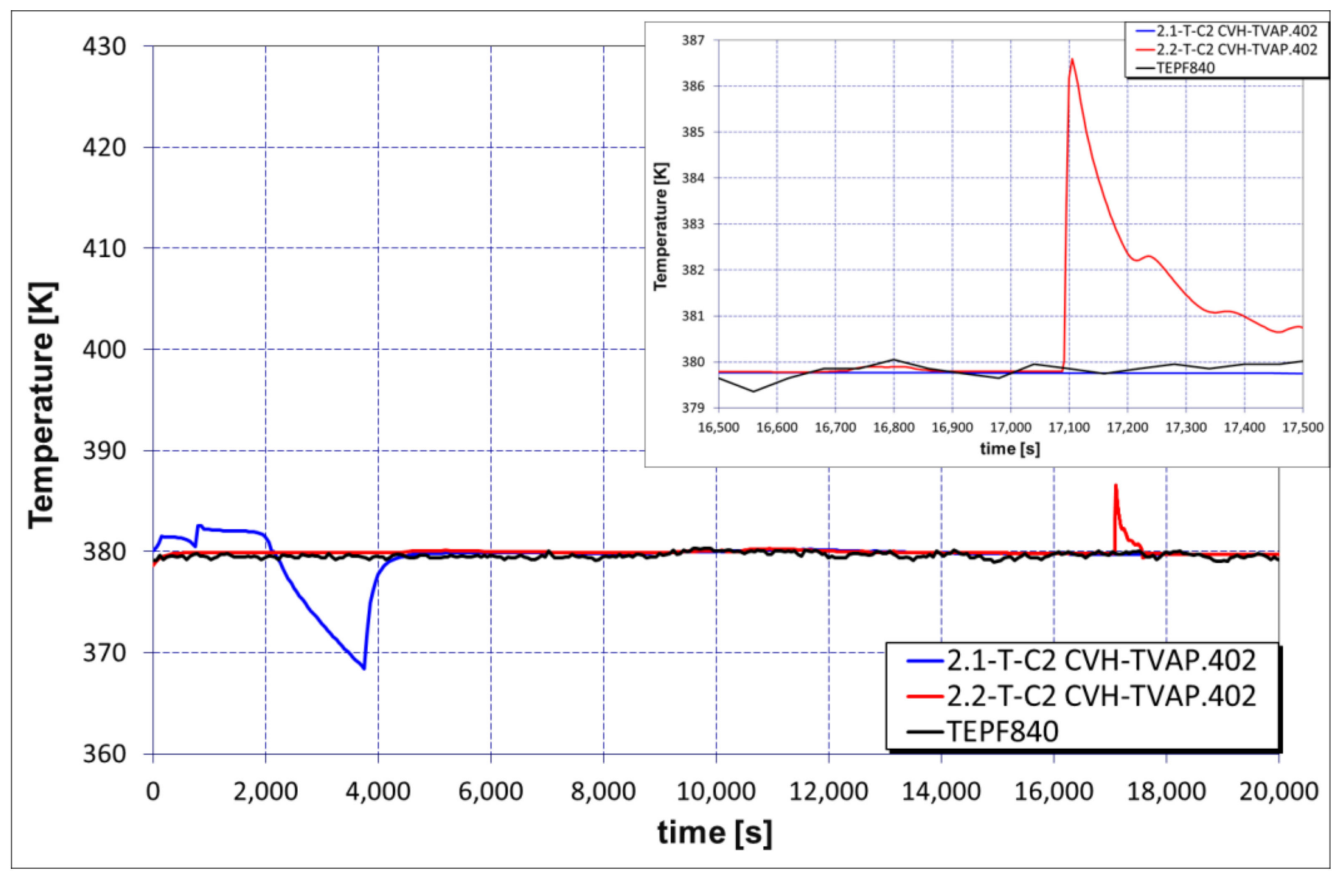

Figure 12. Active channel temperature-containment.

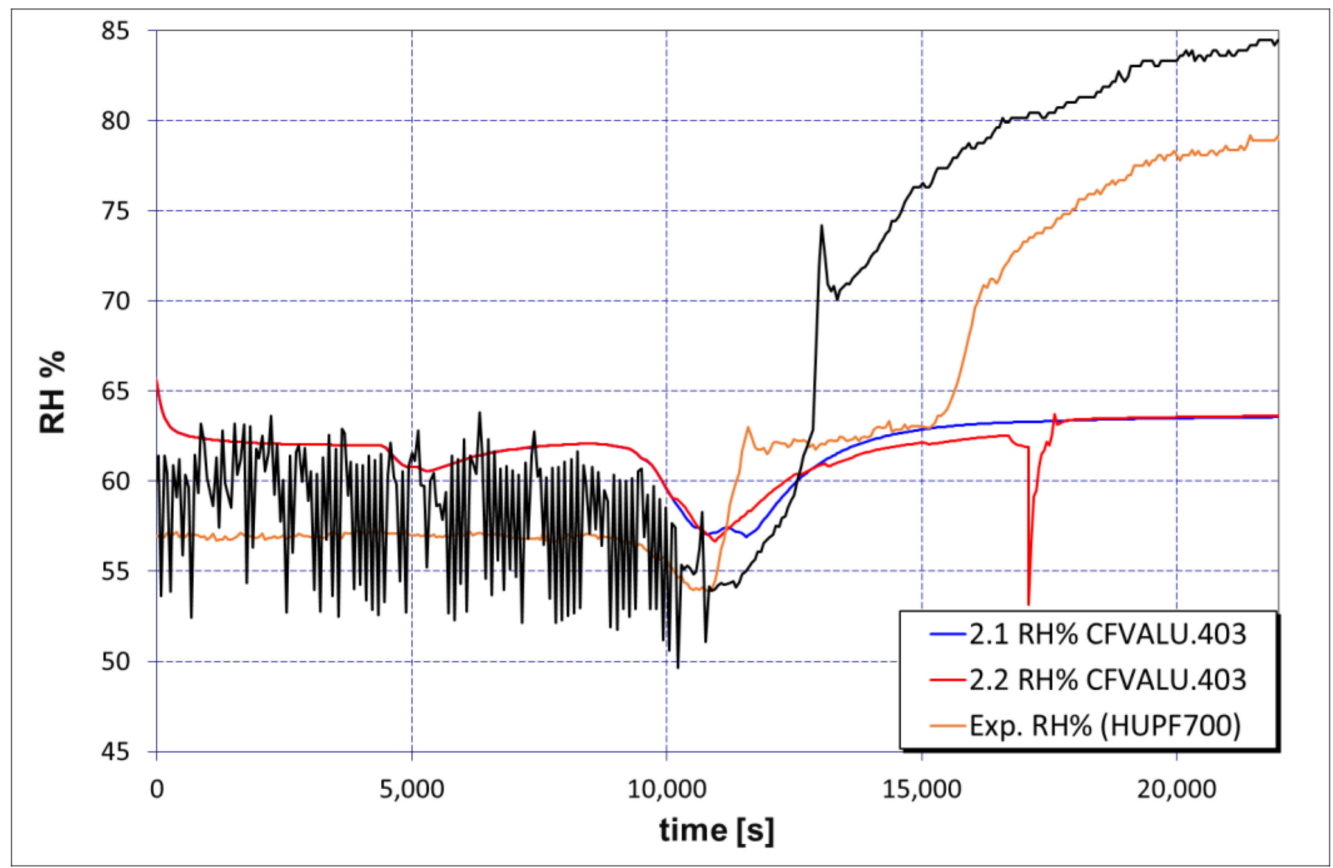

Figure 13. Relative humidity in the sump.

\subsubsection{Hydrogen Production}

For the MELCOR 2.1, the simulation shows an early hydrogen release around $4000 \mathrm{~s}$ (see Figure 14) this early release in the simulation could be due to the reaction of the control rod (boron carbide) with the steam. A second hydrogen release was detected around $8500 \mathrm{~s}$ similar to the experiment and finally a third hydrogen release peak was reached around $12,700 \mathrm{~s}$. 


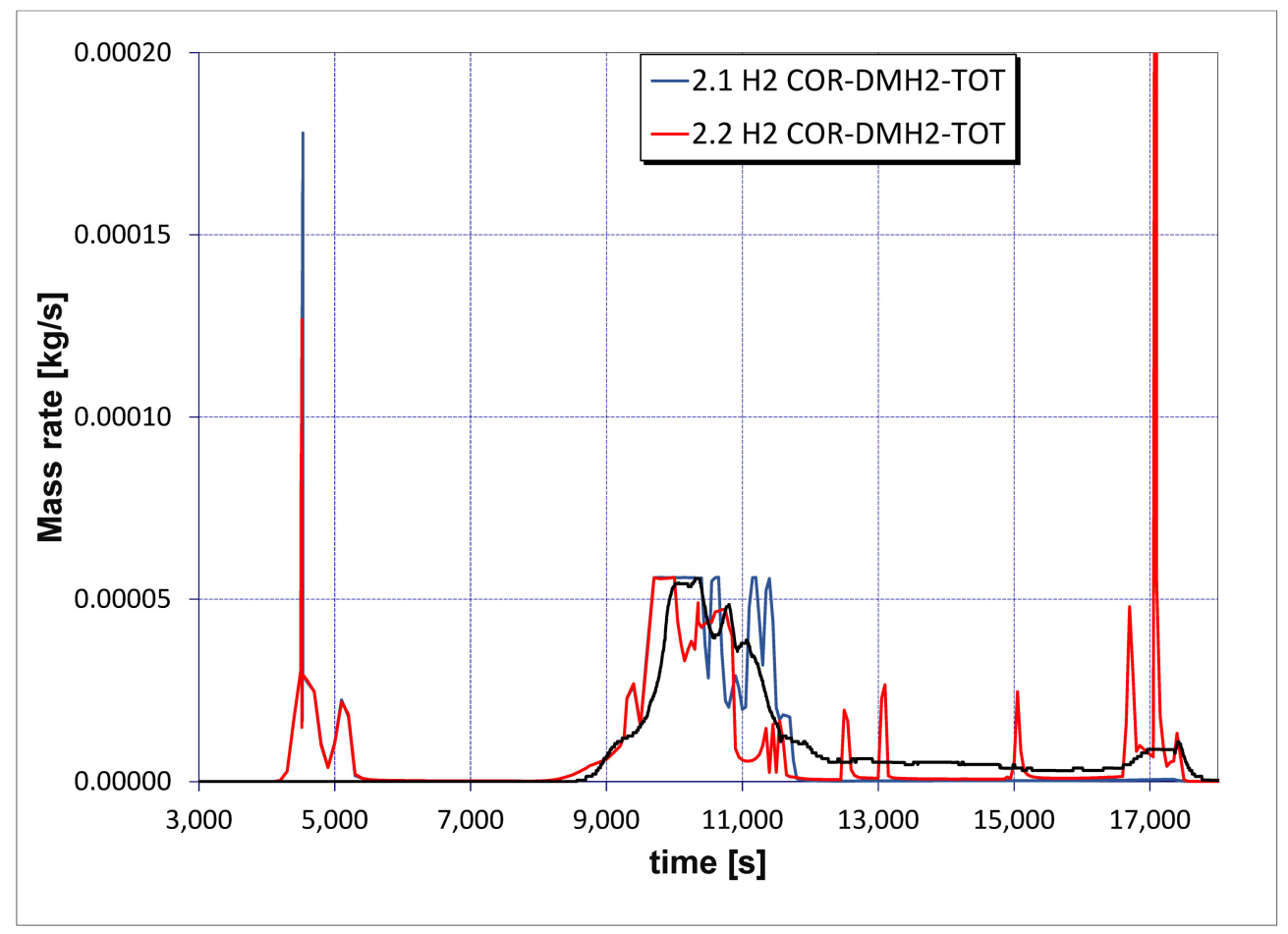

Figure 14. Hydrogen production rate.

Despite to the early hydrogen release and the third hydrogen release, the total amount of hydrogen produced $(0.122 \mathrm{~kg})$ was similar to the experiment $(0.119 \mathrm{~kg})$. That is equivalent to the overestimation of $2.14 \%$ of hydrogen production compared to the experiment. (see Figure 15).

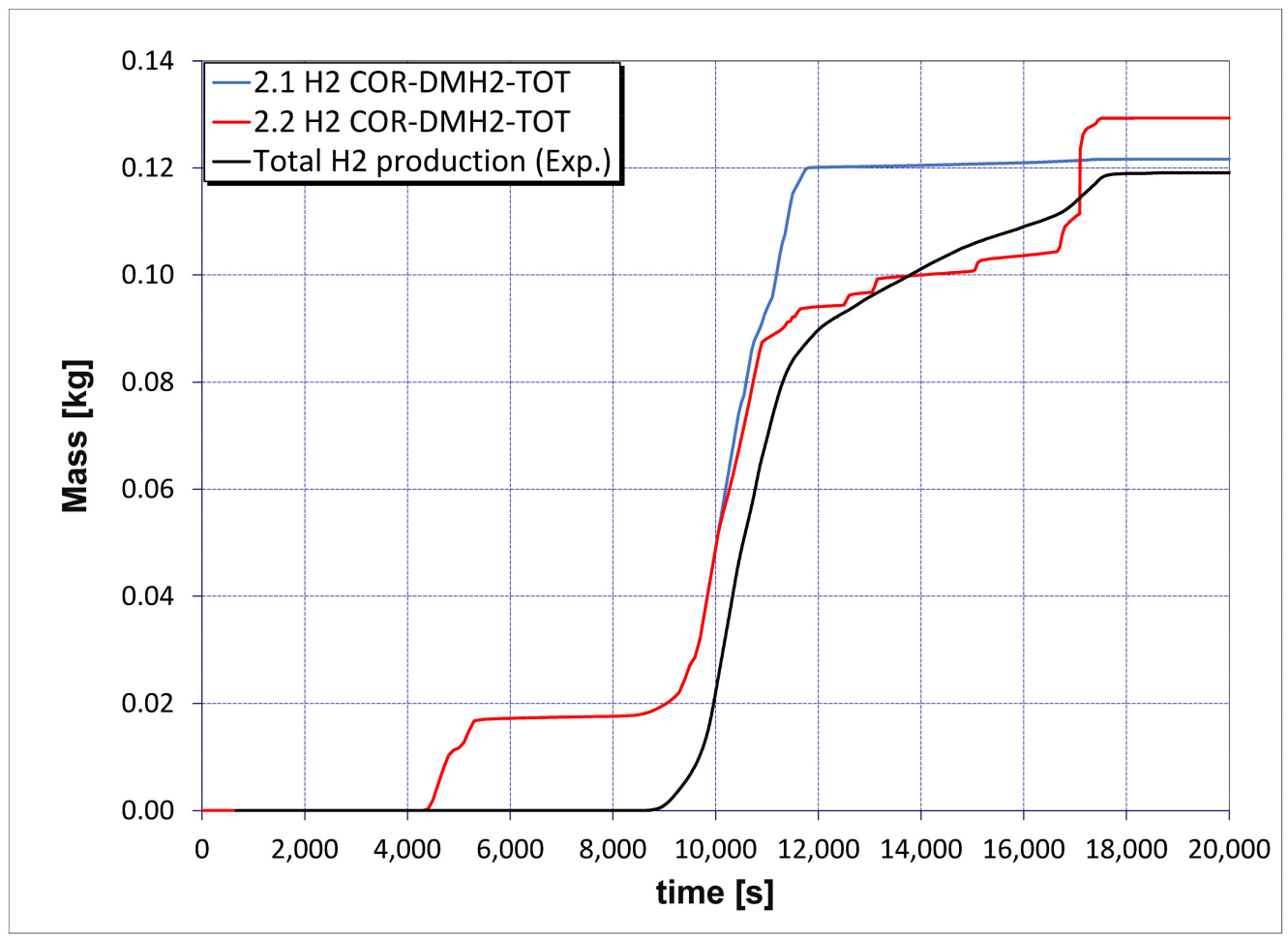

Figure 15. Total hydrogen production. 
In fact, the hydrogen production reached around $0.120 \mathrm{~kg}$ as in FPT2, with approximately $16.66 \%$ originating from the boron carbide reactions. At $10,000 \mathrm{~s}$, when the hydrogen production rate raised to the limit of steam starvation, the cladding of $\mathrm{B}_{4} \mathrm{C}$ started to degrade and prepares the control rod to react with the steam, producing hydrogen, $\mathrm{CO}$, methane, $\mathrm{CO}_{2}$, and boric acid. Due to the very exothermic reaction of steam with $\mathrm{B}_{4} \mathrm{C}$ as with zirconium the temperature of the bundle increases.

On the other hand, for the MELCOR version 2.2 the results of the hydrogen production were similar to the MELCOR version 2.1 from the beginning of the simulation until around $10,000 \mathrm{~s}$ where the hydrogen production decreases, compared to the version 2.1, and follow the experimental course as can be seen in the Figure 15. Finally, around 17,000 s there is a peak that over predicts the total hydrogen production until a total of $129.3 \mathrm{~g}$. That is equivalent to an $8.59 \%$ overestimation in hydrogen production compared with the experiment.

\subsubsection{Core Mechanics}

In the experiment, temperature starts to increase and around $4900 \mathrm{~s}$ and it underlines the fuel rod ruptures with the early source term release. At $8700 \mathrm{~s}$, the oxidation phase and the consequent hydrogen generation started, around $t=9550 \mathrm{~s}$ the $\mathrm{B}_{4} \mathrm{C} \mathrm{CR}$ breaks introducing a significant production of heat that increases the molten processes such as candling and reallocation and the interaction of melt with the neighbouring fuel rods. At around $t=10,250 \mathrm{~s}$, the melt relocation forms a small molten pool around the lower grid. The pool blocks some central channels and a steam diversion (blue arrows in Figures 16C and 17D) flow appears underling a choking of the flow area. At around 10,350 s the steam starvation ends followed by a significant release of carbon compounds release at around 10,500 s. At $16,600 \mathrm{~s}$, the first melt progression below the lower grid is registered leading to additional $\mathrm{H}_{2}$ release. In the final phase of the bundle degradation, at around 17,330 s, a second significant melt relocation appears at the lower grid underlined as the starting of molten pool formation.

Both MELCOR code versions, 2.1 and 2.2 are capable to follow the progression of relocation of bundle materials during the degradation phase (up to 18,000 s). However, they predict a different relocation mechanics in comparison with the experimental results. The models tried to reach a similar core mechanical behaviour than in the experiment. Figure 16 shows the evolution of the simulation. Each figure is divided into four sections, at the left side is included the whole facility overview showing the bundle temperature and the hydrogen release which was measured. The second section shows the core degradation and the third section shows the fuel bundle temperature profile ( 2 fuel rods). The last section displays the bundle status.

Figure 16A shows an early hydrogen release, a second hydrogen release can be observed in Figures 16B and 16C shows a third $\mathrm{H}_{2}$ release that coincides with the hydrogen release in the experiment. A small molten pool can be observed in the lower grid, as it was predicted in the experiment. Finally Figure 16D shows the maximum fuel temperature reached $(2670 \mathrm{~K})$ just before the SCRAM.

The same simulation was performed for MELCOR code version 2.2. The results are showed in the Figure 17. From the beginning of the simulation to around 10,000 s, both versions of the MELCOR code show a very similar behaviour. This can be observed also in Figure 15, where the production of hydrogen is identical. After 10,000 s, the production of hydrogen decreases. This behaviour is very similar to the experiment. Figure 17D shows the maximum temperature reached $(2570 \mathrm{~K})$ before the failure of the fuel. The default parameters of the fuel temperature failure were used but they can be changed according to the need of the user. An intense peak of hydrogen release was detected at $\sim 17,000 \mathrm{~s}$. Moreover, the relocation of the melted fuel can be observed. Finally, Figure 17F shows the end state of the simulation, where most of the hydrogen stored in the containment and the core degradation can be observed. At the end of the degradation state simulations underline a similar relocation as in the experiment. 


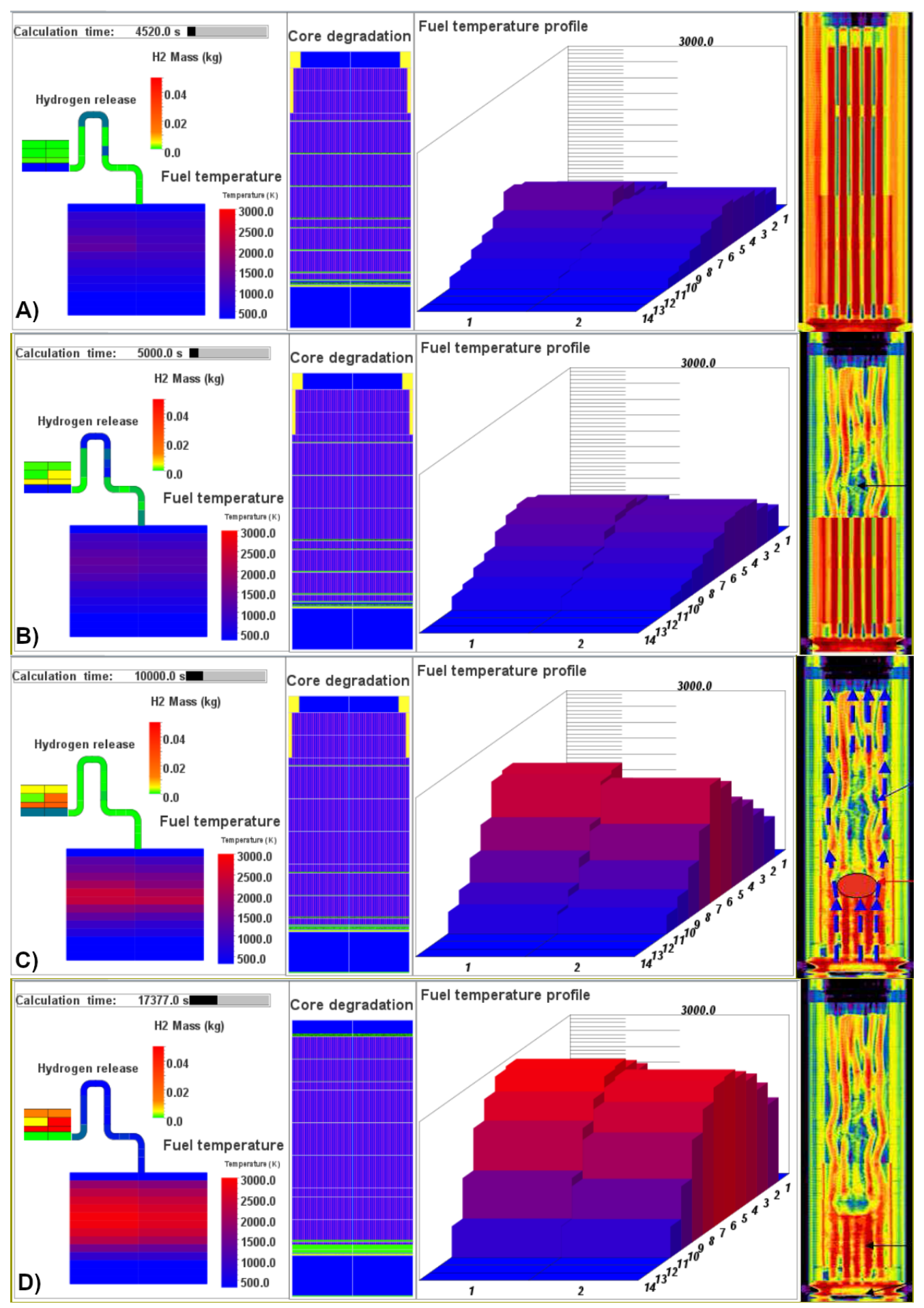

Figure 16. Evolution of the simulation of the FPT3 experiment with MELCOR 2.1. (A) Early H2 release, (B) 2nd $\mathrm{H}_{2}$ release, (C) 3rd $\mathrm{H}_{2}$ release, (D) maximum fuel temperature just before SCRAM. 

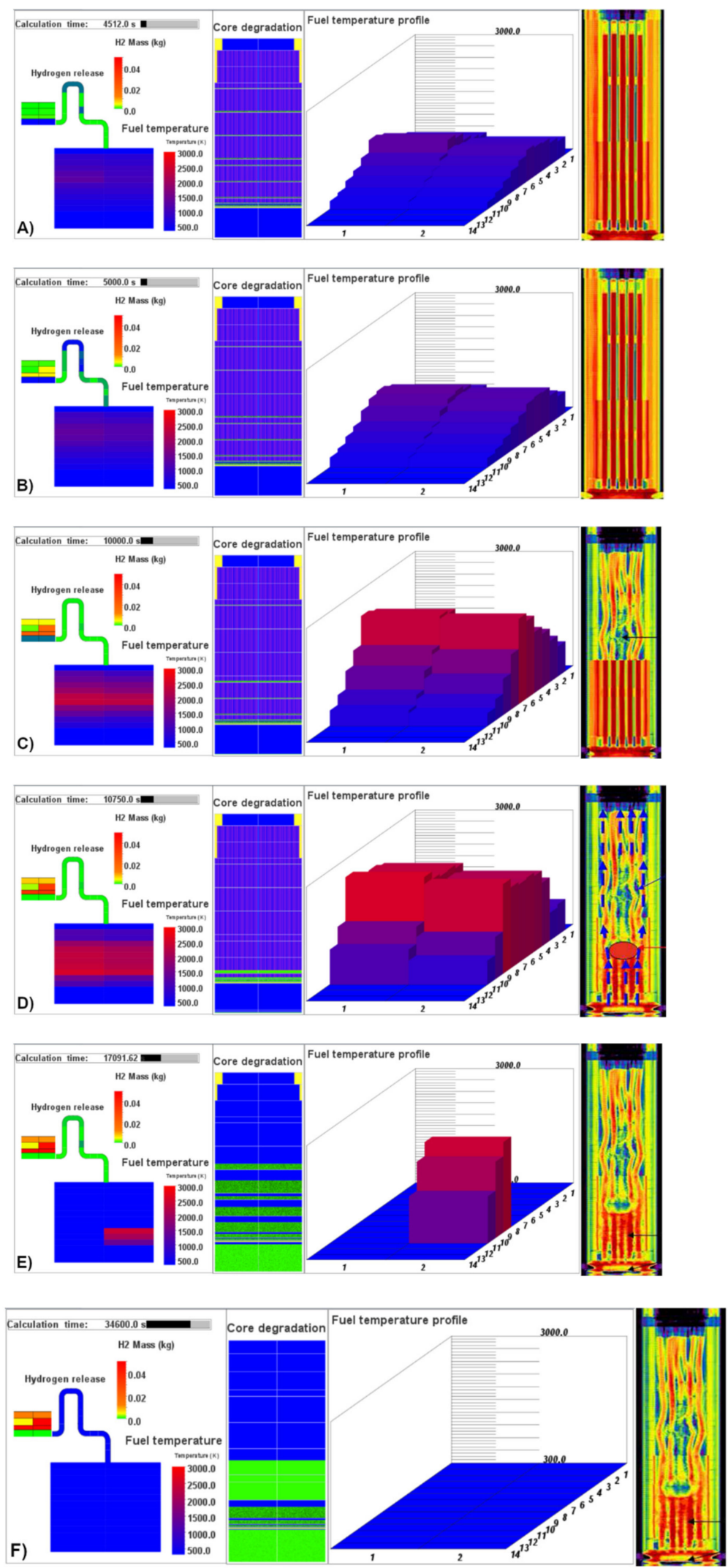

Figure 17. Evolution of the simulation of the FPT3 experiment with MELCOR 2.2. (A) Early $\mathrm{H}_{2}$ release, (B) 2nd $\mathrm{H}_{2}$ release, (C) $3 \mathrm{rd} \mathrm{H}_{2}$ release, (D) maximum fuel temperature just before SCRAM, (E) 4 th $\mathrm{H}_{2}$ release, (F) end state. 


\subsubsection{FP Release (Point C-Hot Leg)}

The control rod material had an important influence on the source term. This was well known from the theoretical point of view at the end of the last century, but first with FPT3 was obtained reference data sets for quantifying the phenomenon. In the future, a high amount of data could be obtained from the post analyses of the Fukushima accident site. Currently, FPT3 is one of the most important tests facilities for codes verification and validation, which is able to simulate the SA progression and estimate the source term.

Another significant particularity of FPT3 is the dimensions of the cavity and "the pool". Except for the wide damage around the control rods, the geometry is preserved due to the low bundle power.

In FPT3 the releases were significant, even though the geometry was almost intact. This depends also from the boric acid and its chemical reaction with zirconium. The premature source term releases during a SA was caused by gases and vapours in the gap and in $\mathrm{UO}_{2}$ matrix, which escaped when the cladding broke down. This source term was assessed to be $20-30 \%$ of the total inventory of vapours and gases as iodine and xenon. After the cladding broke down (at around 10,000 s), iodine, caesium and other volatile materials escaped from the bundle and travelled to the test facility lines. In FPT3 the iodine injected into the containment was $80 \%$ of the total iodine released from the bundle due to the absence of silver. The releases in FPT3 were less than the other tests due to the significant geometry integrity of the bundle.

This profile of the bundle is justified from the temperature trends (Figure 7) of the fuel during the test: the fuel temperature was lower than in FPT2 and it is clear that it is directly proportional to the bundle power.

MELCOR is able to predict the mass of these gasses produced from the reaction and to describe their behaviour in the primary circuit and in the containment vessel.

The radionuclides package (RN) operates on the basis of material classes, which are groups of elements that have similar chemical properties, the MELCOR version 2.1 and 2.2 have 17 classes (see Table 4).

Table 4. RN class composition [9].

\begin{tabular}{|c|c|c|c|c|}
\hline Class & Class Name & Chemical Group & Representative & Member Elements \\
\hline 1 & $\mathrm{XE}$ & Noble Gas & $\mathrm{Xe}$ & $\mathrm{He}, \mathrm{Ne}, \mathrm{Ar}, \mathrm{Kr}, \mathrm{Xe}, \mathrm{Rn}, \mathrm{H}, \mathrm{N}$ \\
\hline 2 & CS & Alkali Metals & CS & $\mathrm{Li}, \mathrm{Na}, \mathrm{K}, \mathrm{Rb}, \mathrm{Cs}, \mathrm{Fr}, \mathrm{Cu}$ \\
\hline 3 & BA & Alkaline Earths & $\mathrm{Ba}$ & $\mathrm{Be}, \mathrm{Mg}, \mathrm{Ca}, \mathrm{Sr}, \mathrm{Ba}, \mathrm{Ra}, \mathrm{Es}, \mathrm{Fm}$ \\
\hline 4 & $\mathrm{I} 2$ & Halogens & $\mathrm{I} 2$ & $\mathrm{~F}, \mathrm{Cl}, \mathrm{Br}, \mathrm{I}, \mathrm{At}$ \\
\hline 5 & $\mathrm{TE}$ & Chalcogens & $\mathrm{Te}$ & $\mathrm{O}, \mathrm{S}, \mathrm{Se}, \mathrm{Te}, \mathrm{Po}$ \\
\hline 6 & RU & Platinoids & $\mathrm{Ru}$ & $\mathrm{Ru}, \mathrm{Rh}, \mathrm{Pd}, \mathrm{Re}, \mathrm{Os}, \mathrm{Ir}, \mathrm{Pt}, \mathrm{Au}, \mathrm{Ni}$ \\
\hline 7 & $\mathrm{MO}$ & Early Transition Elements & Mo & $\mathrm{V}, \mathrm{Cr}, \mathrm{Fe}, \mathrm{Co}, \mathrm{Mn}, \mathrm{Nb}, \mathrm{Mo}, \mathrm{Tc}, \mathrm{Ta}, \mathrm{W}$ \\
\hline 8 & $\mathrm{CE}$ & Tetravalents & $\mathrm{Ce}$ & $\mathrm{Ti}, \mathrm{Zr}, \mathrm{Hf}, \mathrm{Ce}, \mathrm{Th}, \mathrm{Pa}, \mathrm{Np}, \mathrm{Pu}, \mathrm{C}$ \\
\hline 9 & LA & Trivalents & $\mathrm{La}$ & $\begin{array}{l}\mathrm{Al}, \mathrm{Sc}, \mathrm{Y}, \mathrm{La}, \mathrm{Ac}, \mathrm{Pr}, \mathrm{Nd}, \mathrm{Pm}, \mathrm{Sm}, \mathrm{Eu}, \mathrm{Gd}, \mathrm{Tb}, \\
\mathrm{Dy}, \mathrm{Ho}, \mathrm{Er}, \mathrm{Tm}, \mathrm{Yb}, \mathrm{Lu}, \mathrm{Am}, \mathrm{Cm}, \mathrm{Bk}, \mathrm{Cf}\end{array}$ \\
\hline 10 & $\mathrm{UO}_{2}$ & Uranium & $\mathrm{UO}_{2}$ & $\mathrm{U}$ \\
\hline 11 & $\mathrm{CD}$ & More Volatile Main Group & $\mathrm{Cd}$ & $\mathrm{Cd}, \mathrm{Hg}, \mathrm{Zn}, \mathrm{As}, \mathrm{Sb}, \mathrm{Pb}, \mathrm{Tl}, \mathrm{Bi}$ \\
\hline 12 & AG & Less Volatile Main Group & $\mathrm{Ag}$ & $\mathrm{Ga}, \mathrm{Ge}, \mathrm{In}, \mathrm{Sn}, \mathrm{Ag}$ \\
\hline 13 & $\mathrm{BO}_{2}$ & Boron & $\mathrm{BO}_{2}$ & $\mathrm{~B}, \mathrm{Si}, \mathrm{P}$ \\
\hline 14 & $\mathrm{H}_{2} \mathrm{O}$ & Water & $\mathrm{H}_{2} \mathrm{O}$ & $\mathrm{H}_{2} \mathrm{O}$ \\
\hline 15 & $\mathrm{CON}$ & Concrete & $\mathrm{CON}$ & - \\
\hline 16 & CSI & Caesium iodide & CsI & CsI \\
\hline 17 & CSM & Caesium Molybdenum & CsM & CsM \\
\hline
\end{tabular}

Figure 18 shows the total FP release in the Point C (hot leg) divided by classes. As in some of the results the differences between the experiment and the MELCOR 2.1 and 2.2 results are significant, hence a secondary axis was used. When two axes appear, the primary axis is reserved for the experiment and the secondary axis for the MELCOR results. 

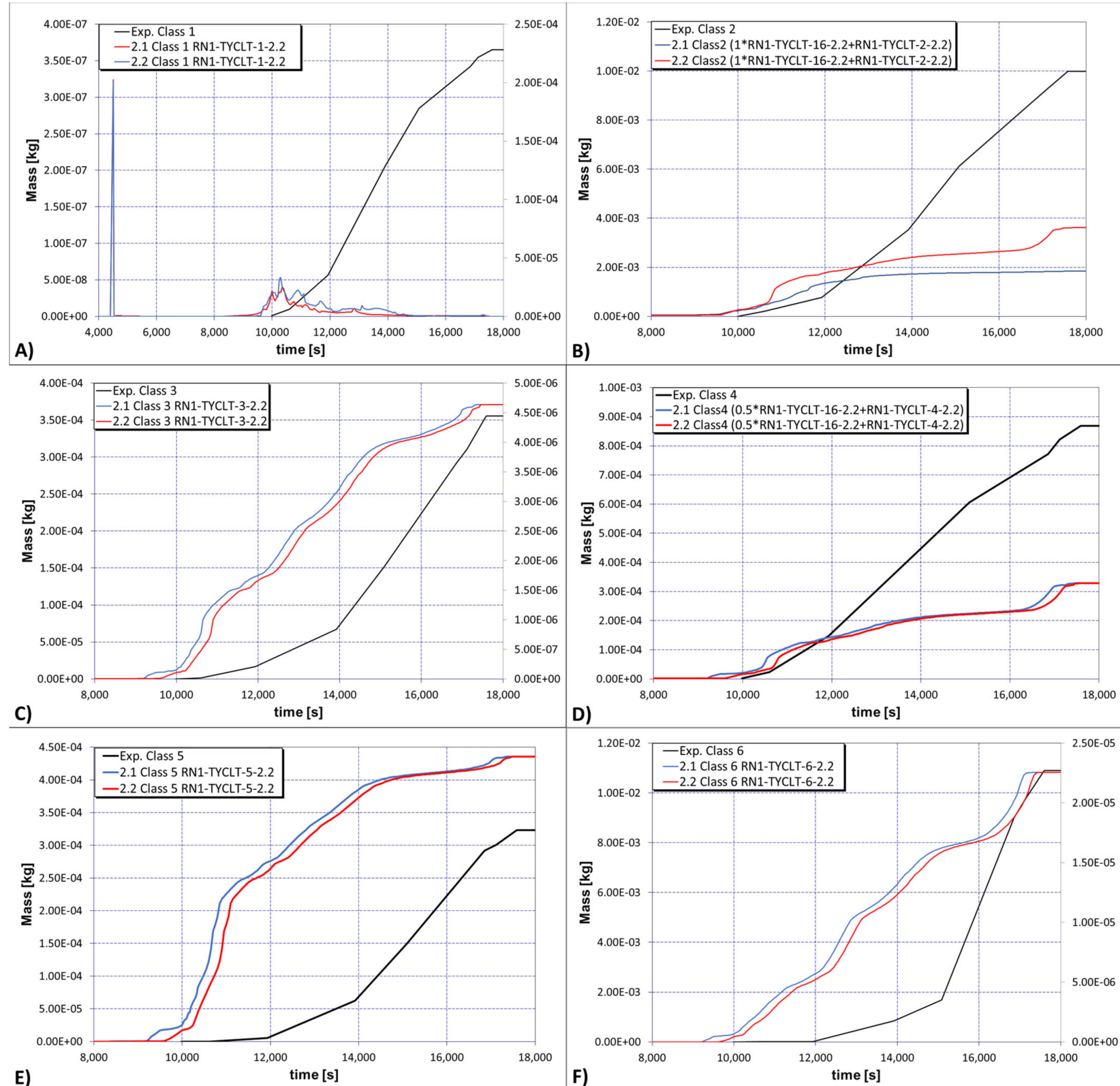

D)
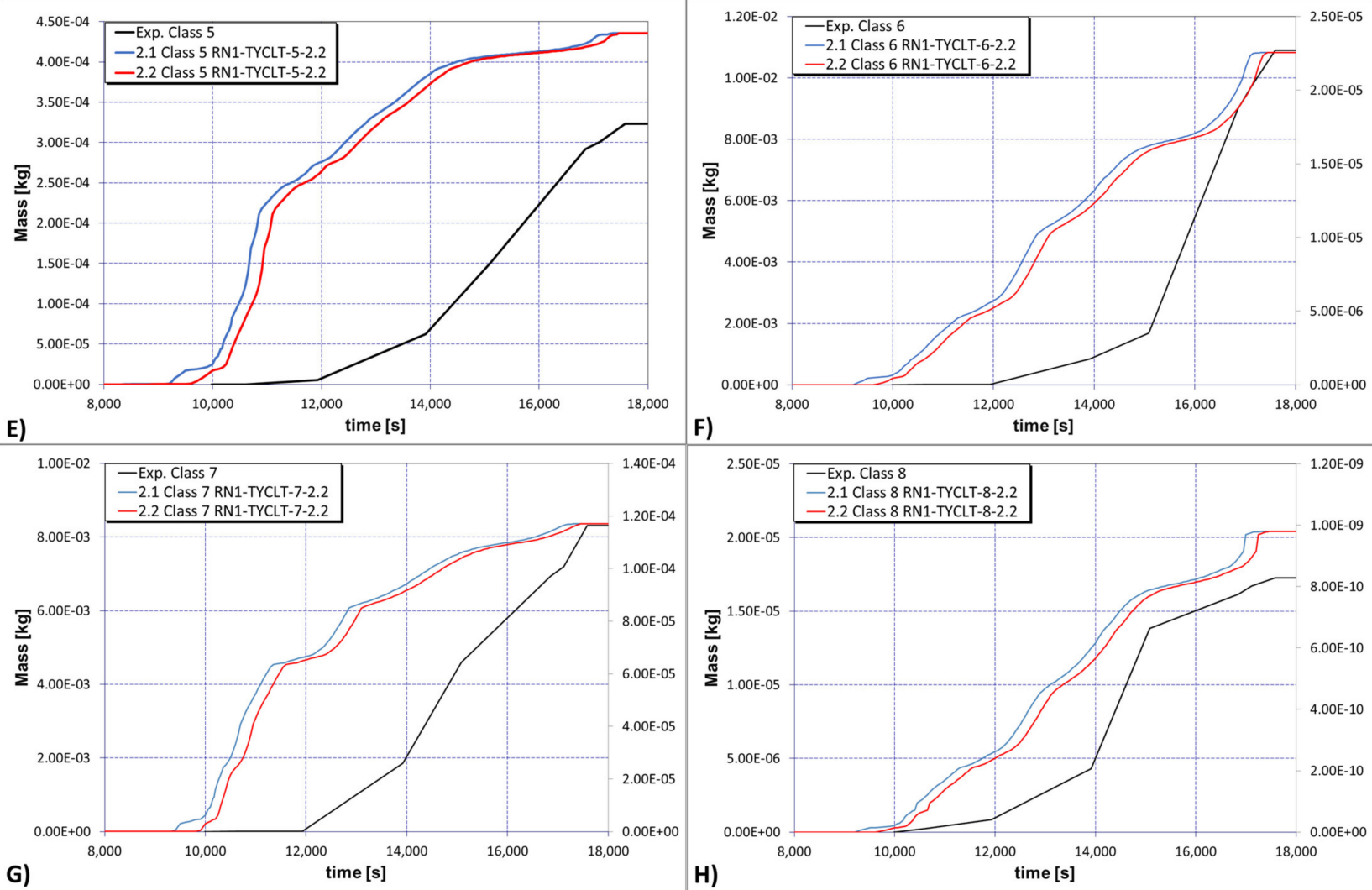

Figure 18. Cont. 


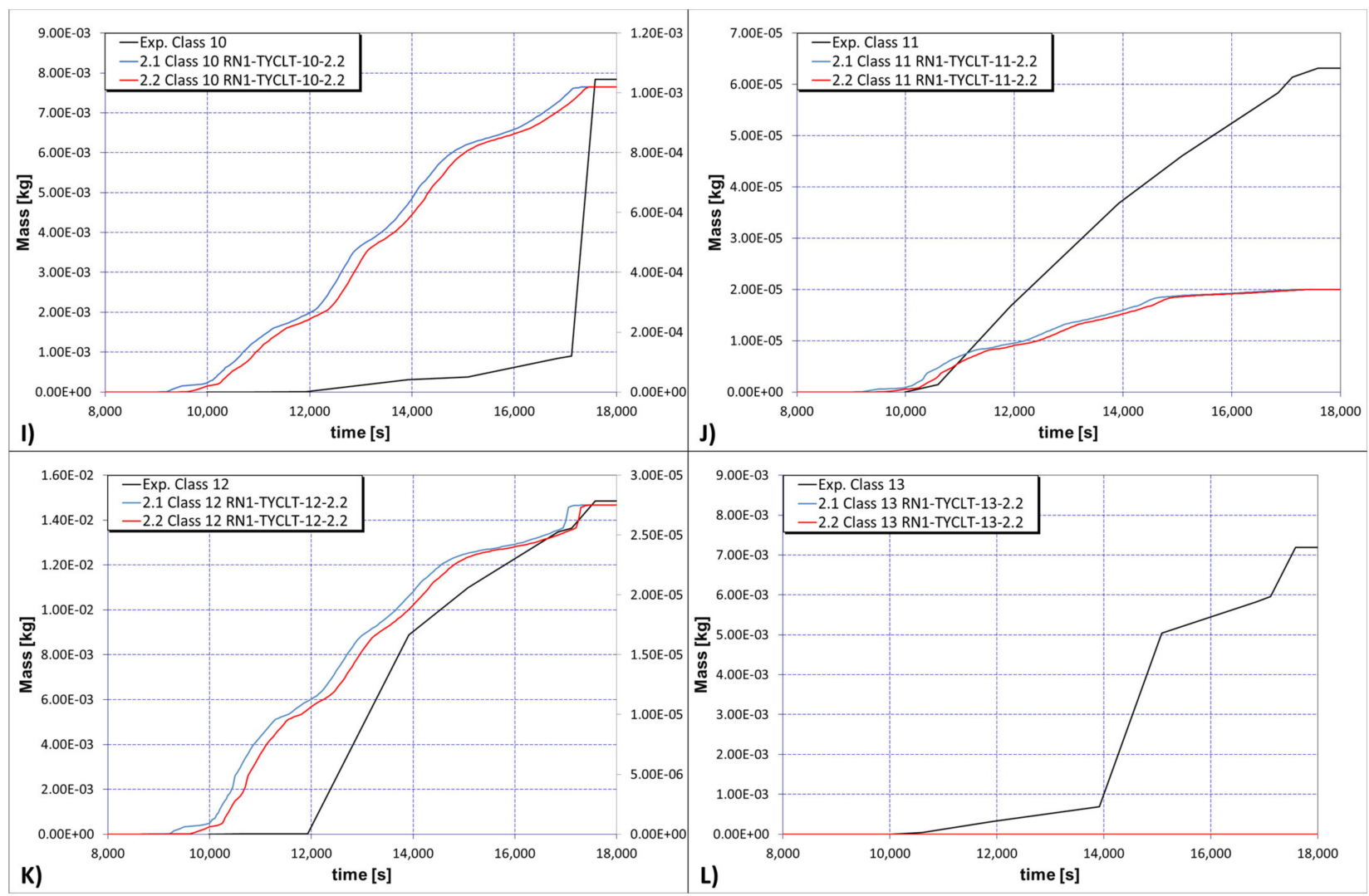

Figure 18. Comparison of classes mass between the experiment and MELCOR.

Following classes are figured separately:

- Class 1 for xenon and krypton as well as hydrogen. Those elements have a low density, hence they will not remain in the Point $C$ and they will flow and will be stored mainly in the containment. At around $4500 \mathrm{~s}$, a peak in Class 1 can be detected that represents the hydrogen release from an early release (see Figure 18A).

- Class 2 is the Class of the alkali metals as rubidium and caesium. The fraction of caesium from Class 16 (CSI) was added to the Class 2 (Figure 18B), taking into account the diatomic molecule of iodine, two molecules of CSI to have 2 molecules of Caesium (2Cs) and one molecule of iodine (I2). Those molecules of iodine were added to the Class 4-Halogens where is included the iodine (Figure 18D).

- Class 3 Alkaline earths includes barium and strontium as vapour and aerosol (Figure 18C).

- Class 5 Includes mainly tellurium (Figure 18E).

- Class 6 Ruthenium and rhenium, as aerosol and vapour (Figure 18F).

- Class 7 Molybdenum and tungsten in aerosol and vapour (Figure 18G).

- Class 8 Plutonium and cerium as aerosol and vapour (Figure 18H).

- Class 10 Mainly includes uranium (Figure 18I).

- Class 11 Antimony and cadmium in aerosol and vapour (Figure 18J).

- Class 12 Mainly silver as aerosol and vapour and finally Class 13 with boron (Figure 18K).

- Class 13 Boron dioxide (Figure 18L).

Table 5 shows the total amount of RNs at Point C (hot leg) compared to the results in MELCOR code version 2.1 and 2.2. The MELCOR version 2.2 have improved the results for Class 7 and Class 10, mainly. The Class 9 was not detected in the experiment but in both versions of MELCOR there are a very small fraction of this class. It is possible that the resolution of the instrumentation in the experiment was not enough to detect the presence of elements of the Class 9. Vice versa, for the Class 1 the total mass inventory that remains in the Point $C$ was simulated significantly lower than the experiment highlighting that this material is completely transported to the containment vessel. On the AC model, there 
are some major differences between code versions results (approximately one order of magnitude) between the Classes 1, 3, 7 and 10. Those differences are due to modifications mainly in the COR package between version 2.1 and version 2.2, where the mechanic of the core relocation influences the releases. MELCOR 2.2 is more conservative from this point of view because it considers higher fuel relocation.

Table 5. Comparison of total classes mass between experiment and MELCOR.

\begin{tabular}{|c|c|c|c|c|}
\hline Class & Exp. $[\mathrm{kg}]$ & MELCOR $2.1[\mathrm{~kg}]$ & MELCOR $2.2[\mathrm{~kg}]$ & MELCOR Variable \\
\hline 1 & $3.65 \times 10^{-7}$ & $5.09 \times 10^{-8}$ & 0 & RN1-TYCLT-1-2.2 \\
\hline 2 & $9.99 \times 10^{-3}$ & $1.57 \times 10^{-3}$ & $3.30 \times 10^{-3}$ & 0.51*RN1-TYCLT-16-2.2+RN1-TYCLT-2-2.2 \\
\hline 3 & $3.55 \times 10^{-4}$ & $1.13 \times 10^{-5}$ & $4.63 \times 10^{-6}$ & RN1-TYCLT-3-2.2 \\
\hline 4 & $8.69 \times 10^{-4}$ & $2.69 \times 10^{-4}$ & $3.22 \times 10^{-4}$ & 0.49*RN1-TYCLT-16-2.2+RN1-TYCLT-4-2.2 \\
\hline 5 & $3.23 \times 10^{-4}$ & $4.15 \times 10^{-4}$ & $4.36 \times 10^{-4}$ & RN1-TYCLT-5-2.2 \\
\hline 6 & $1.09 \times 10^{-2}$ & $1.70 \times 10^{-5}$ & $2.26 \times 10^{-5}$ & RN1-TYCLT-6-2.2 \\
\hline 7 & $8.31 \times 10^{-3}$ & $7.28 \times 10^{-6}$ & $1.17 \times 10^{-4}$ & RN1-TYCLT-7-2.2 \\
\hline 8 & $1.73 \times 10^{-5}$ & $8.43 \times 10^{-10}$ & $9.80 \times 10^{-10}$ & RN1-TYCLT-8-2.2 \\
\hline 9 & - & $5.23 \times 10^{-10}$ & $5.38 \times 10^{-10}$ & RN1-TYCLT-9-2.2 \\
\hline 10 & $7.84 \times 10^{-3}$ & $8.94 \times 10^{-4}$ & $1.02 \times 10^{-3}$ & RN1-TYCLT-10-2.2 \\
\hline 11 & $6.32 \times 10^{-5}$ & $1.74 \times 10^{-5}$ & $2.00 \times 10^{-5}$ & RN1-TYCLT-11-2.2 \\
\hline 12 & $1.49 \times 10^{-2}$ & $2.12 \times 10^{-5}$ & $2.75 \times 10^{-5}$ & RN1-TYCLT-12-2.2 \\
\hline 13 & $7.19 \times 10^{-3}$ & 0 & 0 & RN1-TYCLT-13-2.2 \\
\hline TOTAL & $6.08 \times 10^{-2}$ & $3.50 \times 10^{-3}$ & $5.60 \times 10^{-3}$ & \\
\hline
\end{tabular}

Indeed, these results are improved but still have some discrepancies with the experimental data. The reason is mainly due to the parametric approach of CORSOR Booth used in MELCOR to simulate the release in high burn-up fuel (more than $32 \mathrm{GWd} / \mathrm{t}$ ). The main differences between MELCOR 2.2 and MELCOR 2.1 is based on the sensitivity coefficient of COR package which leads to an intensive damage of the fuel assembly and providing the boundary conditions for radionuclide $(\mathrm{RN})$ package.

\subsubsection{FP Elements Injected into the Containment}

The mass of aerosols injected into the containment vessel was estimated at around $13.6 \mathrm{~g}$ calculated from the available measurements at Point $\mathrm{G}$ and Point $\mathrm{H}$. In addition to aerosols, an important mass of noble gases ( $\mathrm{Kr}$ and $\mathrm{Xe}$ ) arrived in the containment during the transient, around $1.9 \mathrm{~g}$ for krypton and $25.4 \mathrm{~g}$ for xenon. Therefore, the total material injected into the containment vessel was estimated at $410 \mathrm{~g}$. Table 6 shows the proportions of different elements injected into the containment.

Table 6. Material injected into the containment vessel during the transient.

\begin{tabular}{|c|c|c|c|c|c|}
\hline & Element & Class & Mass [mg] & $\begin{array}{c}\text { \% Initial Inventory } \\
{[\% \text { i.i }]}\end{array}$ & $\begin{array}{c}\text { Estimated Relative } \\
\text { Uncertainty [\%] }\end{array}$ \\
\hline \multirow{2}{*}{ Noble Gas } & $\mathrm{Kr}$ & 1 & 1924 & 74 & 17 \\
\hline & $\mathrm{Xe}$ & 1 & 25,430 & 81.5 & 16 \\
\hline \multirow{18}{*}{ Fission Product } & $\mathrm{Ba}$ & 3 & 67 & 0.590 & 17 \\
\hline & Cs & 2 & 3961 & 24.8 & 31 \\
\hline & I & 4 & 406 & 34.1 & 17 \\
\hline & $\mathrm{Te}$ & 5 & 124 & 4.5 & 17 \\
\hline & Mo & 7 & 3132 & 13.5 & 18 \\
\hline & $\mathrm{Ag}$ & 12 & 30.6 & 17.5 & 22 \\
\hline & $\mathrm{Cd}$ & 11 & 36 & 21.7 & 20 \\
\hline & $\mathrm{Ce}$ & 8 & 5 & 0.031 & 31 \\
\hline & $\mathrm{Nd}$ & 9 & 0.4 & 0.01 & 30 \\
\hline & $\mathrm{Pd}$ & 6 & 0.9 & 0.025 & 32 \\
\hline & $\operatorname{Pr}$ & 9 & 0.1 & 0.002 & 30 \\
\hline & $\mathrm{Ru}$ & 6 & 31 & 0.270 & 17 \\
\hline & $\mathrm{Rb}$ & 2 & 471 & 17.1 & 17 \\
\hline & $\mathrm{Sr}$ & 3 & 16 & 0.3 & 18 \\
\hline & Y & 9 & 0.09 & 0.003 & 24 \\
\hline & $\mathrm{Tc}$ & 7 & 16 & 0.29 & 20 \\
\hline & $\mathrm{La}$ & 9 & 0.9 & 0.011 & 30 \\
\hline & $\mathrm{Sb}$ & 11 & 6 & 11.8 & 31 \\
\hline
\end{tabular}


Table 6. Cont.

\begin{tabular}{cccccc}
\hline & Element & Class & Mass [mg] & $\begin{array}{c}\text { \% Initial Inventory } \\
{[\% \text { i.i] }}\end{array}$ & $\begin{array}{c}\text { Estimated Relative } \\
\text { Uncertainty [\%] }\end{array}$ \\
\hline Control Rod & $\mathrm{B}$ & 13 & 1347 & 2.3 & 17 \\
& $\mathrm{Sn}$ & 12 & 1620 & 3.1 & 20 \\
Structure material & $\mathrm{Zr}$ & 8 & 50 & 0.0013 & 22 \\
& $\mathrm{~W}$ & 7 & 1015 & 0.37 & 18 \\
& $\mathrm{Re}$ & 6 & 1234 & 0.272 & 20 \\
\hline \multirow{2}{*}{ Fuel } & $\mathrm{U}$ & 10 & 65 & 0.0007 & 36 \\
& $\mathrm{Pu}$ & 8 & 0.7 & \\
\hline Total aerosol & (Without noble gas) & $13,635.69$ & \\
\hline Total material & (With noble gas) & $40,989.69$ & \\
\hline
\end{tabular}

The elements were grouped in classes to allow comparing with the MELCOR results. Table 7 shows the comparison among the experiment and the two MELCOR versions.

Table 7. Material injected into the containment vessel during the transient.

\begin{tabular}{|c|c|c|c|c|c|}
\hline \multirow{2}{*}{ Class } & \multirow{2}{*}{$\begin{array}{c}\text { Experiment } \\
{[\mathrm{kg}]}\end{array}$} & \multirow{2}{*}{$\begin{array}{c}\text { Estimated Relative } \\
\text { Uncertainty }\end{array}$} & \multicolumn{2}{|c|}{ MELCOR } & \multirow{2}{*}{ MELCOR Variable } \\
\hline & & & $\mathrm{AC} * 2.1[\mathrm{~kg}]$ & $\mathrm{AC} * 2.2[\mathrm{~kg}]$ & \\
\hline 1 & $2.74 \times 10^{-2}$ & 16.1 & $3.31 \times 10^{-2}$ & $3.33 \times 10^{-2}$ & RN1-TYCLT-1-2.5 \\
\hline 2 & $4.43 \times 10^{-3}$ & 29.5 & $9.16 \times 10^{-3}$ & $1.09 \times 10^{-2}$ & $\begin{array}{c}0.51 * \text { RN1-TYCLT-16-2.5+RN1- } \\
\text { TYCLT-2-2.5 }\end{array}$ \\
\hline 3 & $8.30 \times 10^{-5}$ & 17.2 & $5.52 \times 10^{-5}$ & $2.48 \times 10^{-5}$ & RN1-TYCLT-3-2.5 \\
\hline 4 & $4.06 \times 10^{-4}$ & 17 & $1.13 \times 10^{-3}$ & $1.16 \times 10^{-3}$ & $\begin{array}{c}0.49^{*} \text { RN1-TYCLT-16-2.5+RN1- } \\
\text { TYCLT-4-2.5 }\end{array}$ \\
\hline 5 & $1.24 \times 10^{-4}$ & 17 & $2.03 \times 10^{-3}$ & $1.97 \times 10^{-3}$ & RN1-TYCLT-5-2.5 \\
\hline 6 & $1.27 \times 10^{-3}$ & 19.9 & $9.27 \times 10^{-5}$ & $1.25 \times 10^{-4}$ & RN1-TYCLT-6-2.5 \\
\hline 7 & $4.16 \times 10^{-3}$ & 18.1 & $3.97 \times 10^{-5}$ & $5.36 \times 10^{-4}$ & RN1-TYCLT-7-2.5 \\
\hline 8 & $5.57 \times 10^{-5}$ & 23 & $4.52 \times 10^{-9}$ & $5.63 \times 10^{-9}$ & RN1-TYCLT-8-2.5 \\
\hline 9 & $1.49 \times 10^{-6}$ & 29.64 & $2.86 \times 10^{-9}$ & $2.99 \times 10^{-9}$ & RN1-TYCLT-9-2.5 \\
\hline 10 & $6.50 \times 10^{-5}$ & 17 & $4.91 \times 10^{-3}$ & $6.03 \times 10^{-3}$ & RN1-TYCLT-10-2.5 \\
\hline 11 & $4.20 \times 10^{-5}$ & 21.57 & $8.74 \times 10^{-5}$ & $1.05 \times 10^{-4}$ & RN1-TYCLT-11-2.5 \\
\hline 12 & $1.65 \times 10^{-3}$ & 20 & $1.15 \times 10^{-4}$ & $1.47 \times 10^{-4}$ & RN1-TYCLT-12-2.5 \\
\hline 13 & $1.35 \times 10^{-3}$ & 17 & 0.00 & 0.00 & RN1-TYCLT-13-2.5 \\
\hline Total & $4.10 \times 10^{-2}$ & & $4.840 \times 10^{-2}$ & $5.190 \times 10^{-2}$ & \\
\hline
\end{tabular}

${ }^{*}$ AC-Active Channel. ${ }^{1}$ The estimated relative uncertainty by Class. It was calculated from the estimated relative uncertainty by element from Table 6 taken into account the element masses for each class.

The Class 1 (noble gasses) had the better results compared with the experiment but on the other hand the Class 10 (uranium) had the largest difference with two order of magnitude. That large difference was compensated with the other classes and at the end the total amount of mass injected into the containment is at least in the same order of magnitude as the MELCOR model results and better than the results obtained in the model without the active channel (see Section 6.2.4).

\subsection{Simulations without Considering the Active Channel}

\subsubsection{Thermohydraulic Behaviour}

The simulation of the imposed released and boundary condition taken from the FPT3 Final Report [25] at the Point $C$ is created in order to see the influence of the core relocation, oxidation, and release models on the thermohydraulic and the fission product transport behaviour. However, the imposed boundary conditions, both code versions present a similar behaviour in the circuit to the model with the bundle degradation simulated, as shown in Figures 19 and 20. The reason of those discrepancies between the Point $C$ results and the experimental data is due to the influence of the thermocouples, which 
was measuring temperature close to the wall instead of the atmosphere bulk temperature, that was simulated in the MELCOR. However, the bulk temperature is one of the most important parameters in the fission products transport, for this reason the results are prioritised to evidence this information.

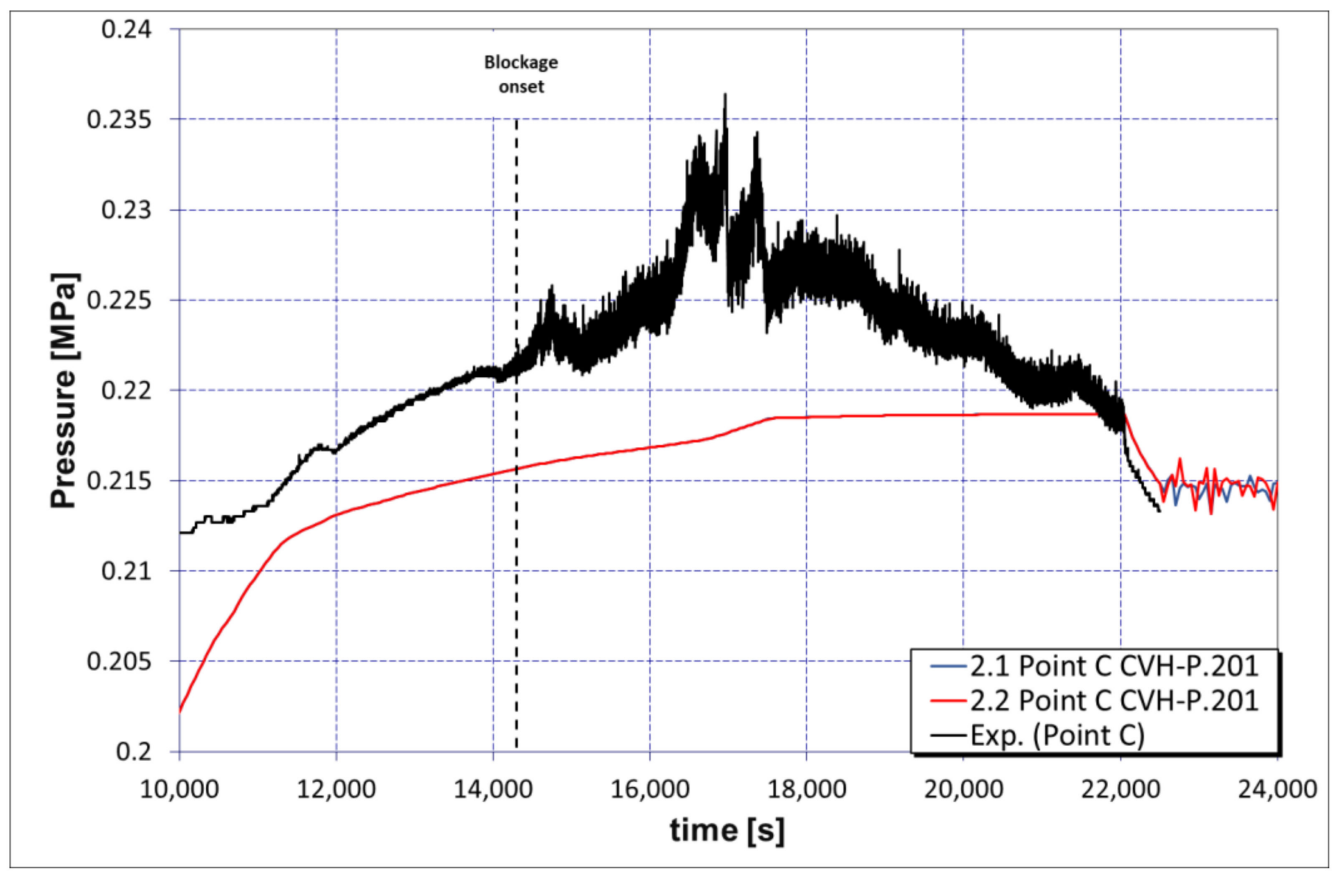

Figure 19. Pressure in Point $C$ (hot leg) of the FPT3 facility (without active channel).

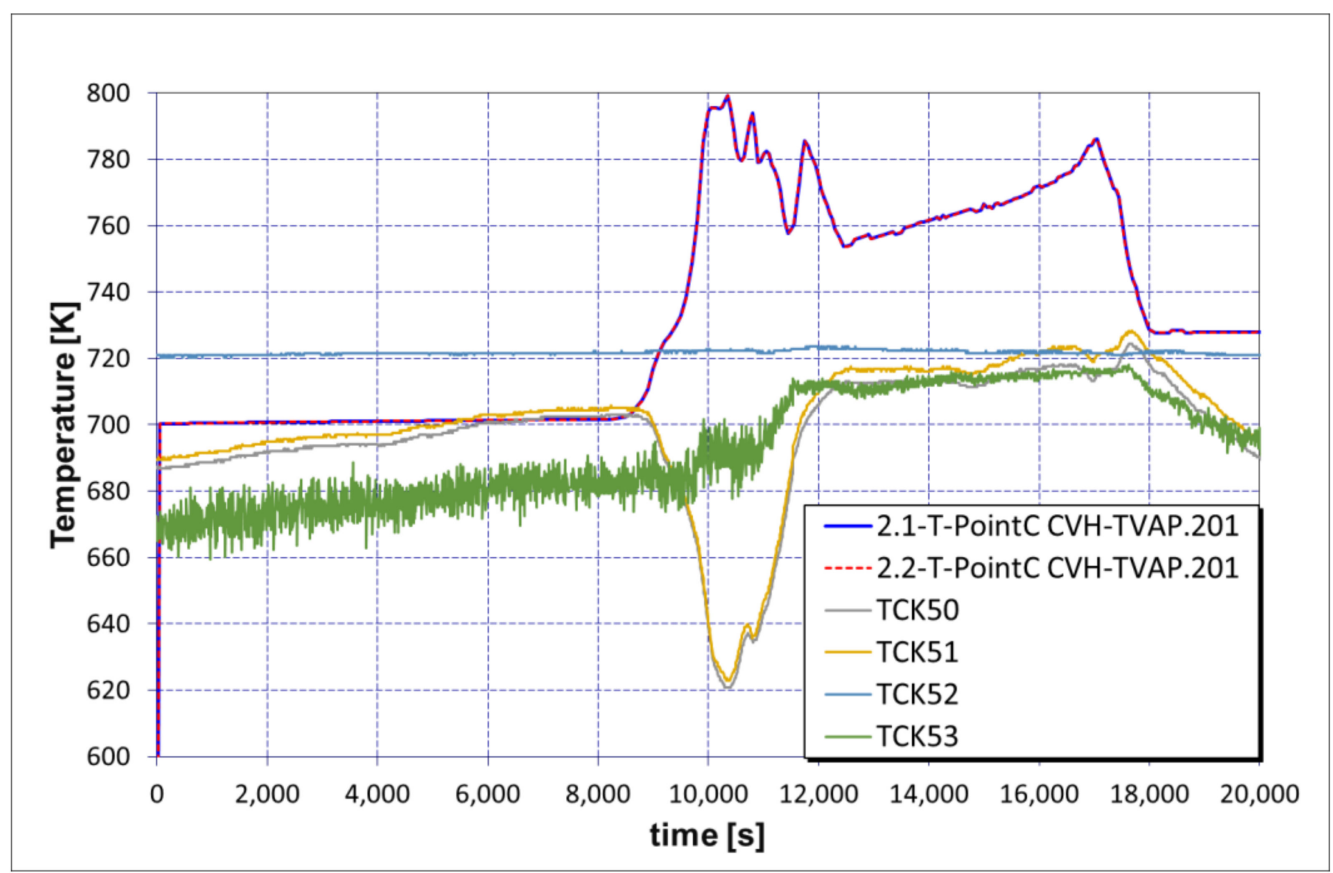

Figure 20. Without active channel temperature-Point C.

Such difference was not significant in the containment thermohydraulic behaviour, as shown in Figures 21-23. The atmosphere temperatures, simulated with MELCOR, have a reasonable shape in comparison to experimental data. However, existing minor discrepancies are equivalent to the underestimation in both codes of the relative humidity 
(as shown in Figure 24) during the simulation of the later degradation phase showing an excessive condensation in comparison to the experimental data.

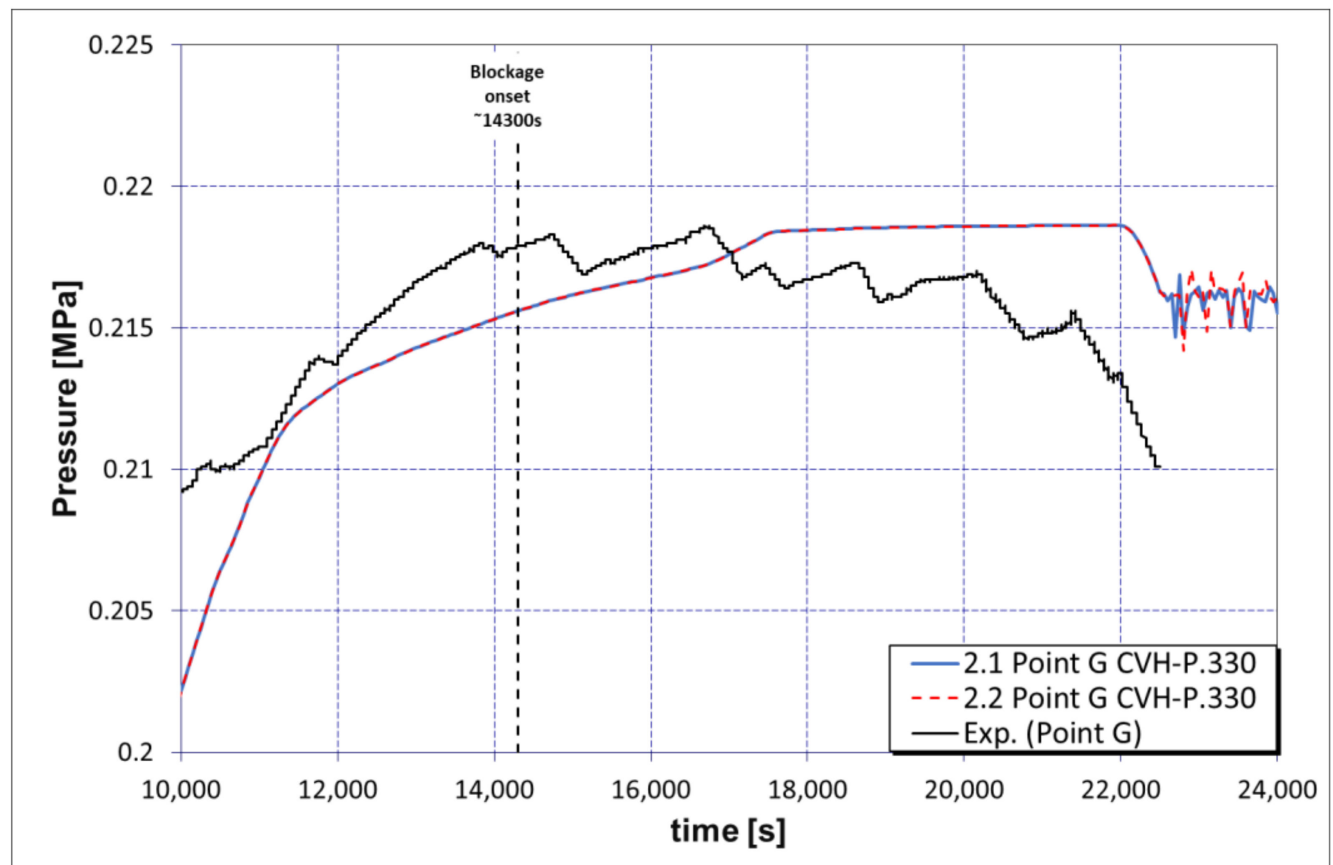

Figure 21. Pressure in Point G (cold leg) of the FPT3 facility (without active channel).

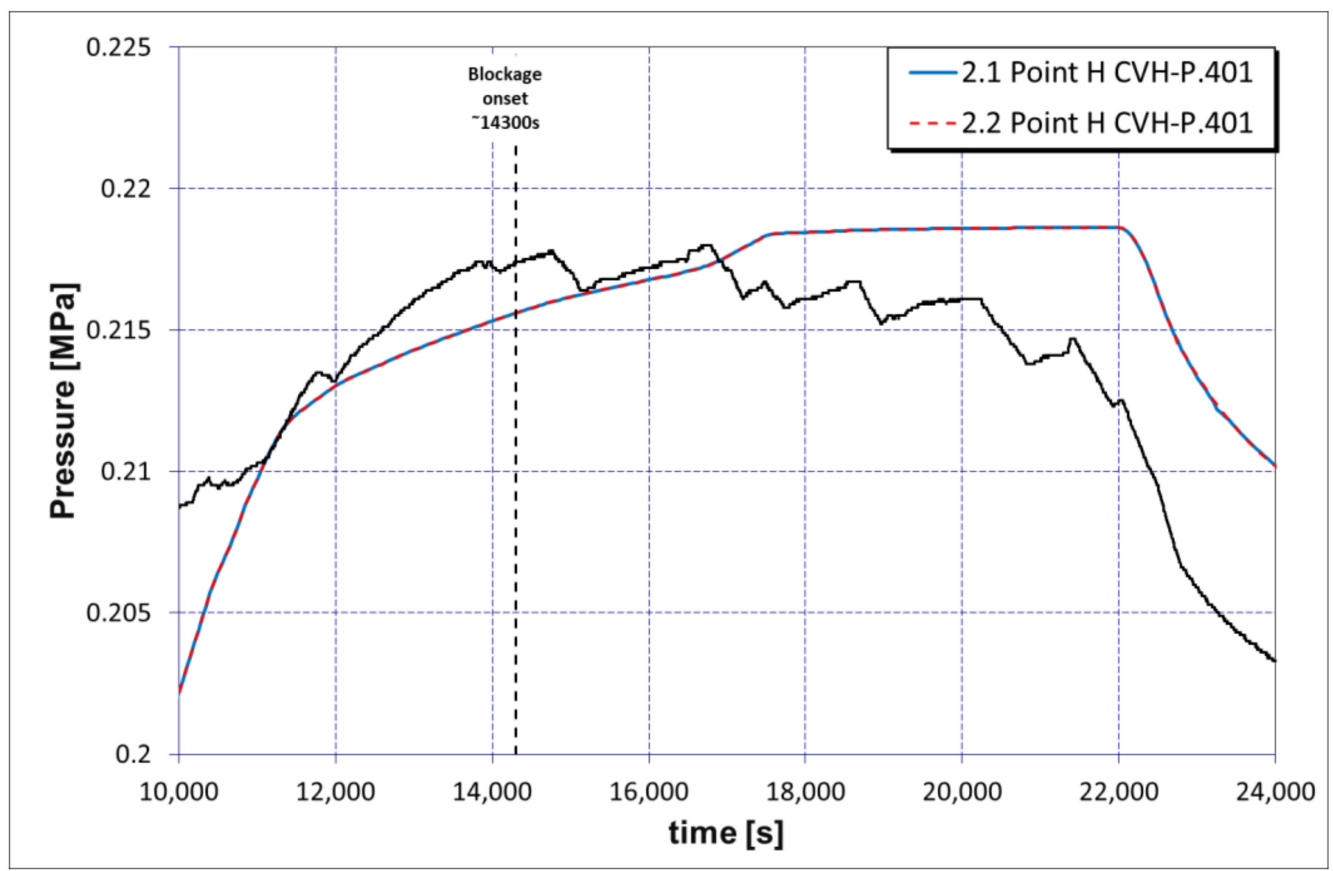

Figure 22. Pressure in Point $\mathrm{H}$ (containment vessel) of the FPT3 facility (without active channel). 


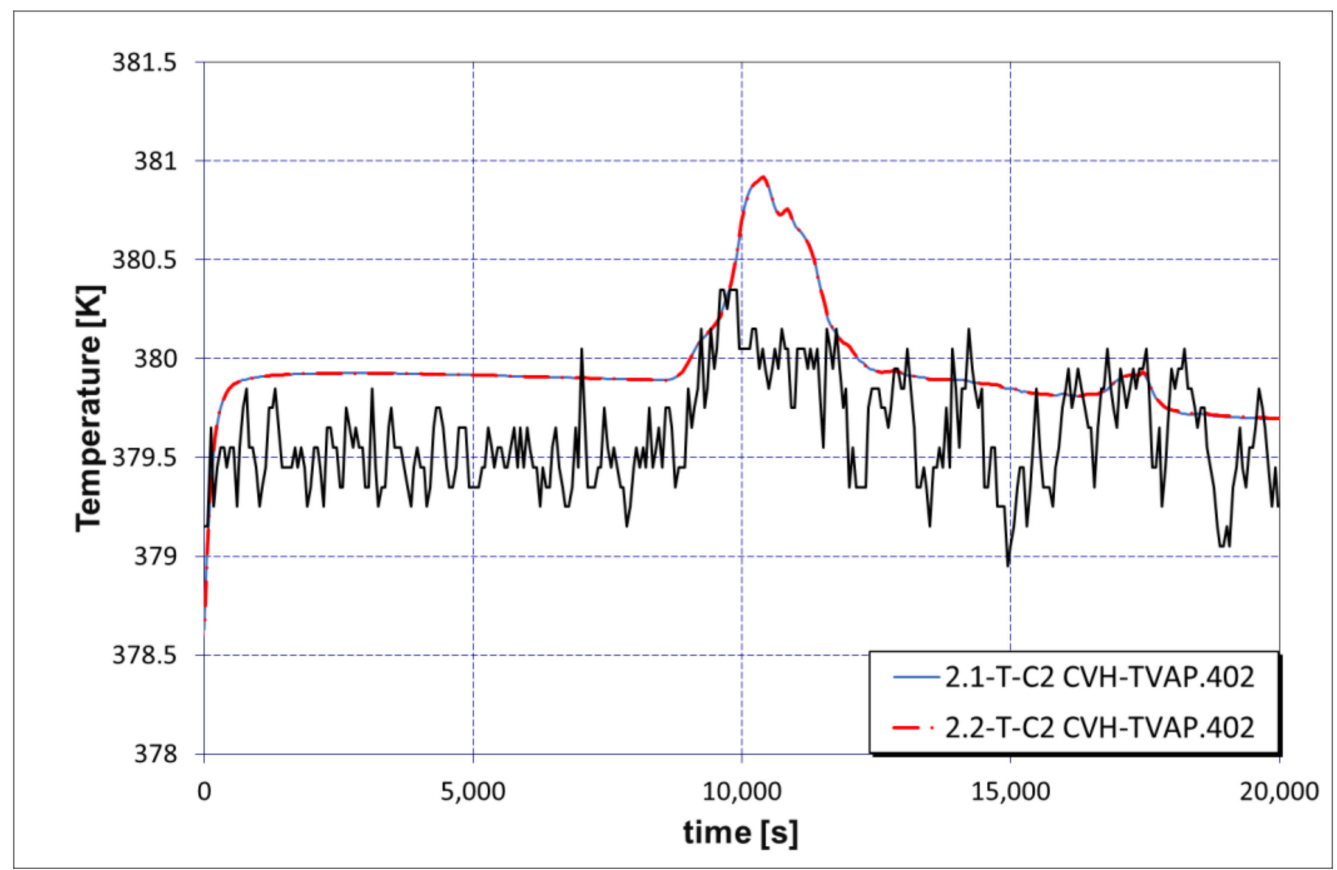

Figure 23. Without active channel temperature-containment.

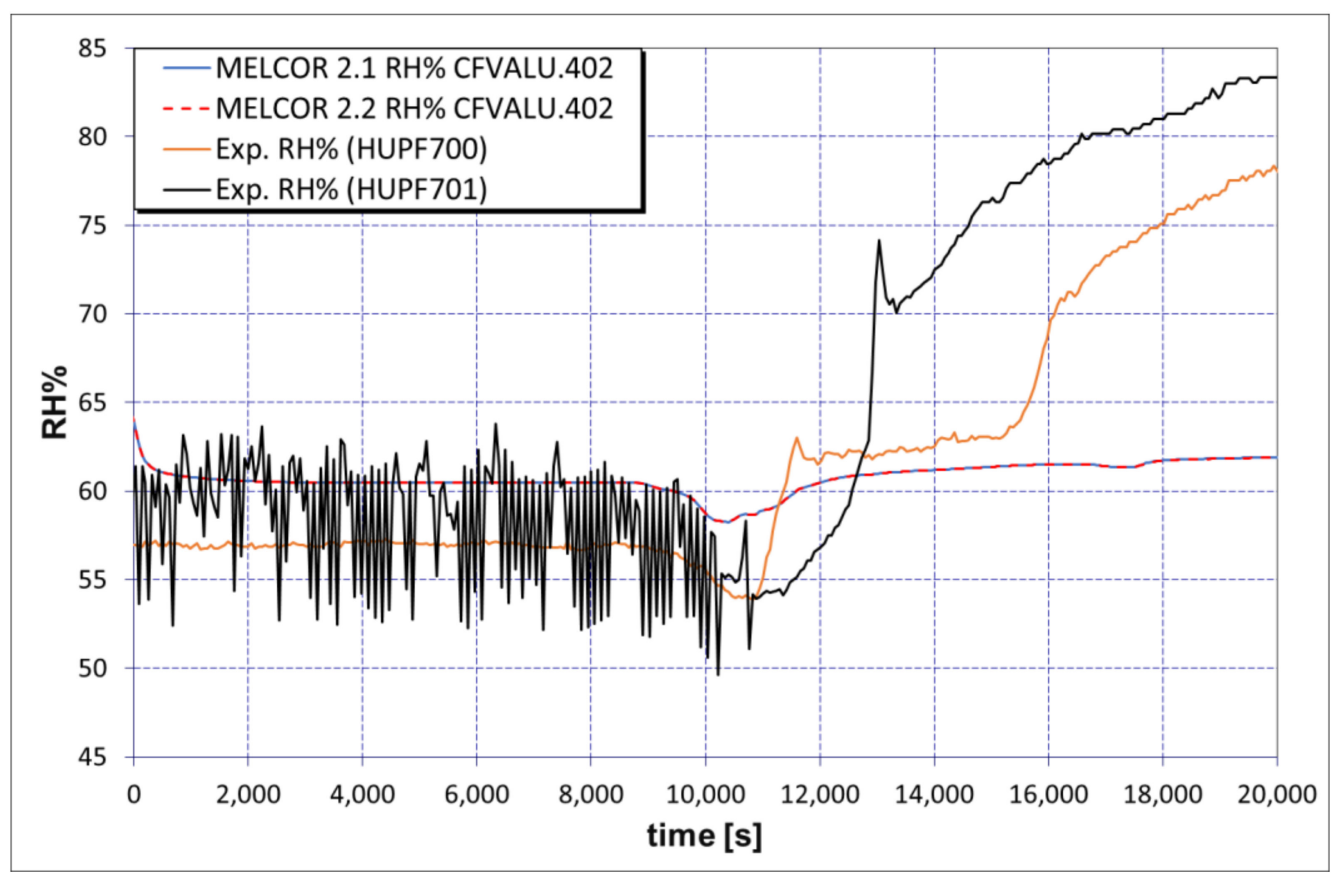

Figure 24. Relative humidity in the sump (without active channel).

\subsubsection{Hydrogen Production}

The aim of this paragraph is to underline the hydrogen production rate as flow rate imposed as boundary condition. The Figure 25 shows this rate measured at the Point $C$ imposed in this model. The presence of the hydrogen rate as non-condensable gas is a key factor for the simulation of the correct thermohydraulic conditions during the transient evolution. The Figure 26 presents the total hydrogen production, where those values fit exactly with the experiment results reducing the influence of inconsistent discrepancies with the boundary conditions extracted from the experiment and inserted in the model. 


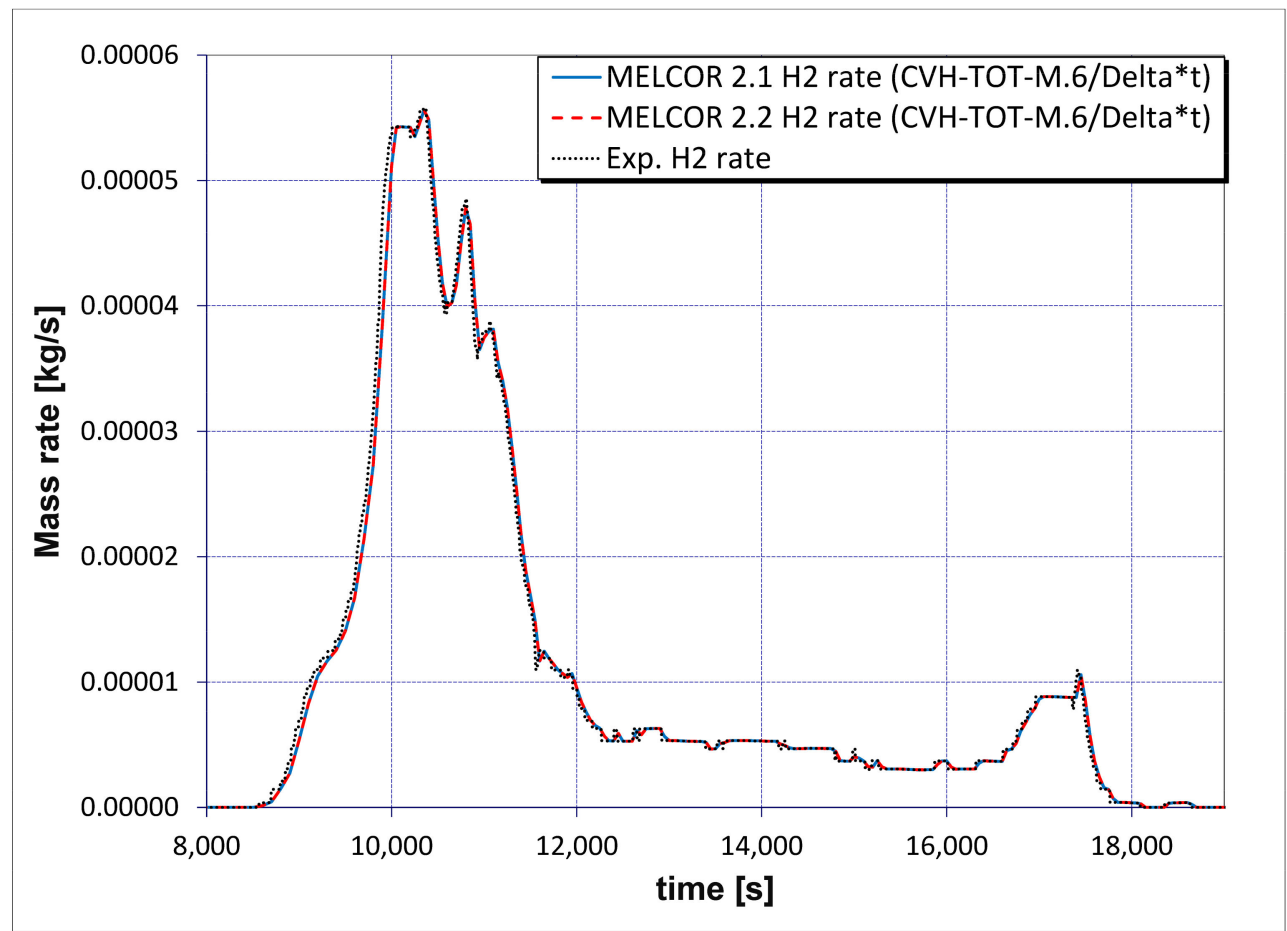

Figure 25. Hydrogen production rate.

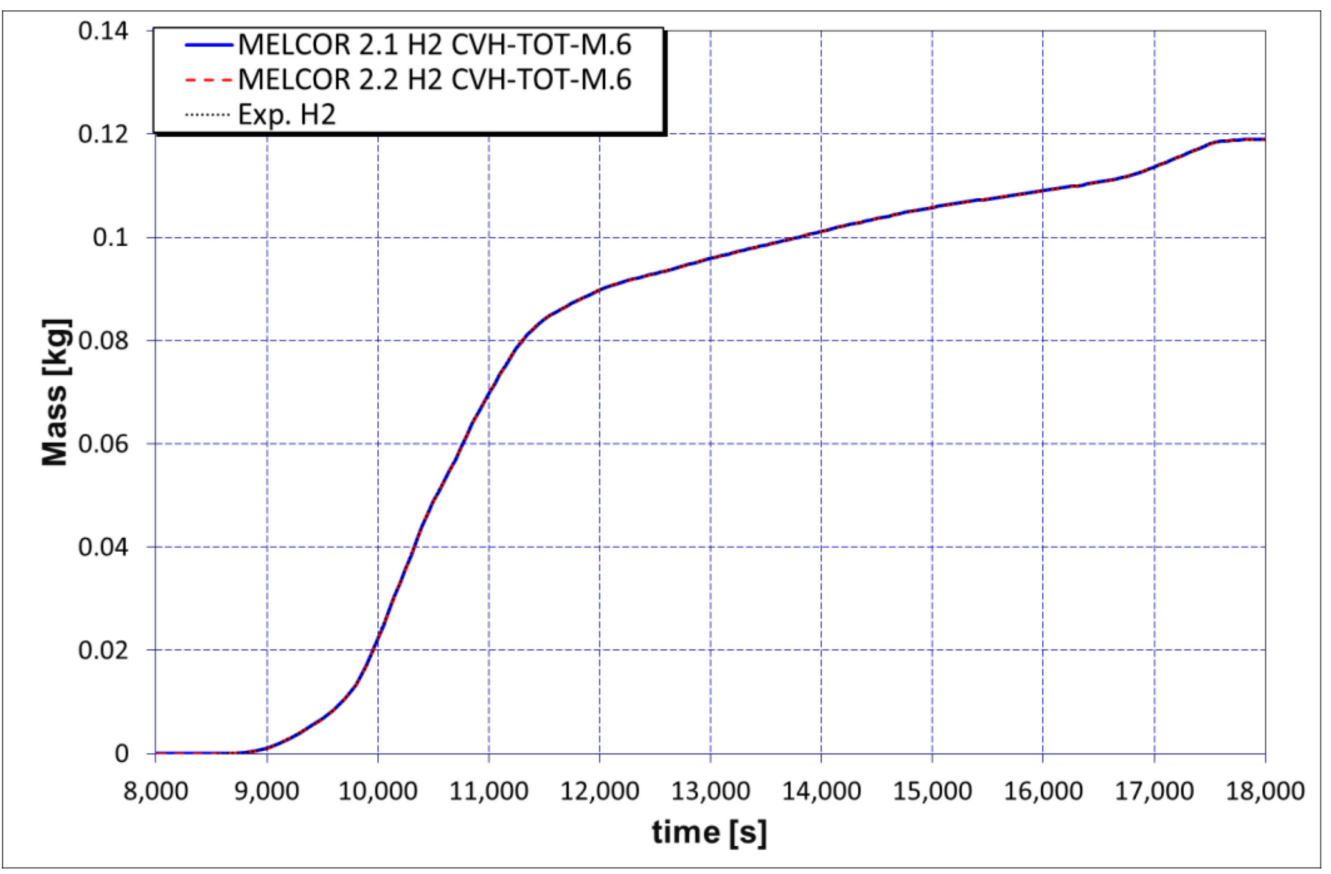

Figure 26. Hydrogen production in the experiment vs. Hydrogen injection in MELCOR.

\subsubsection{FP release (Point $\mathrm{C}$ - Hot Leg)}

The active channel was removed from the model and a mix of steam, hydrogen and radionuclides was injected into the upper plenum as it was measured in the experiment (see Figure 6). This model was applied to avoid the uncertainties related to aerosol deposition along the test circuit. As said before, the active channel was removed in this model and the flow rate for each element released was included in the input deck through tabular functions depending on the time, as was reported in the experiment results. 
The results of the simulation are showed in the Figure 27 and compared with the experimental results. Despite including exactly the same flow rate as in the experimental results, the simulation shows an increase in the total amount of mass for each class, except for the classes 10 and 12 (see Figure 27I,K), where the simulation reaches maximum values compared with the experimental results.
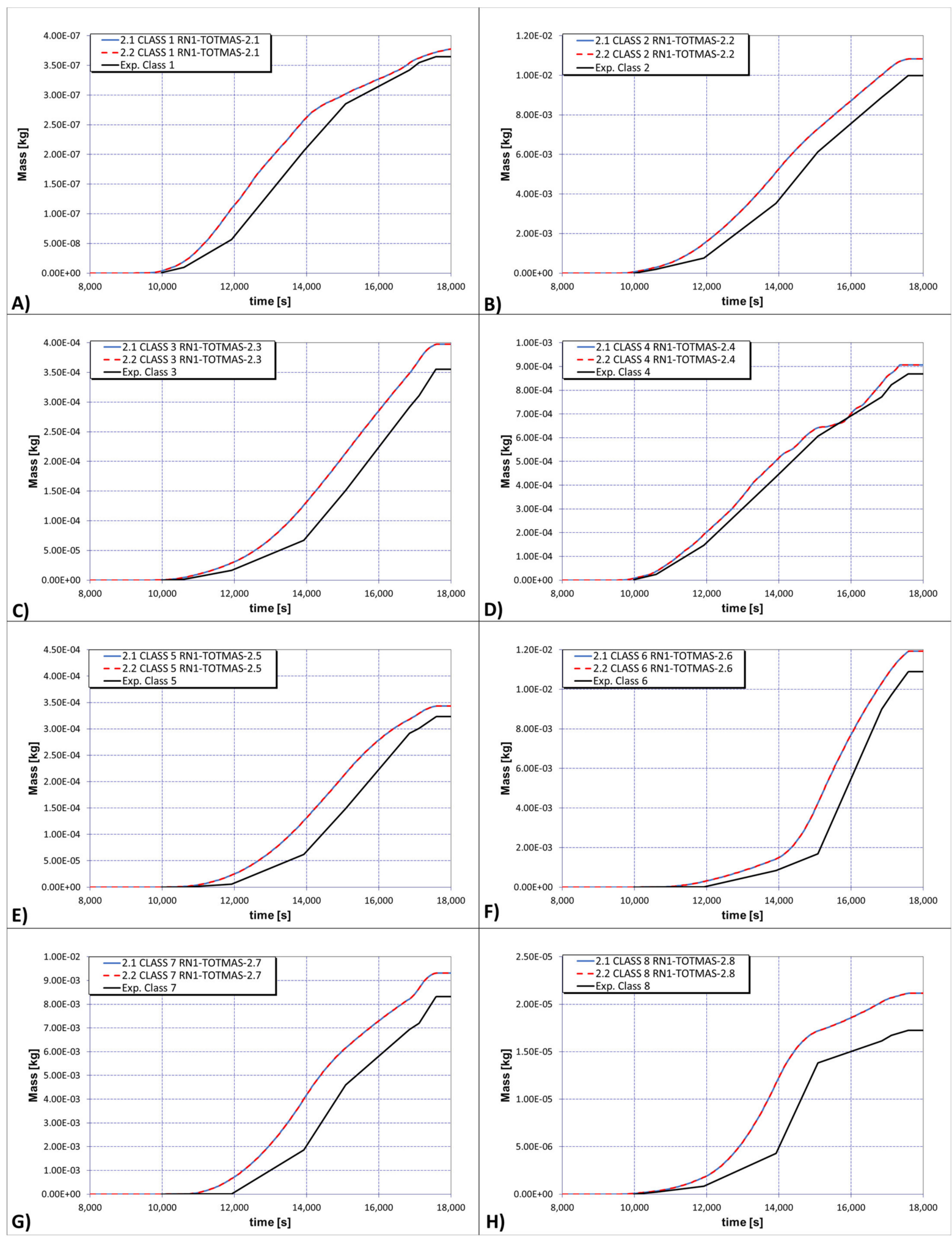

Figure 27. Cont. 

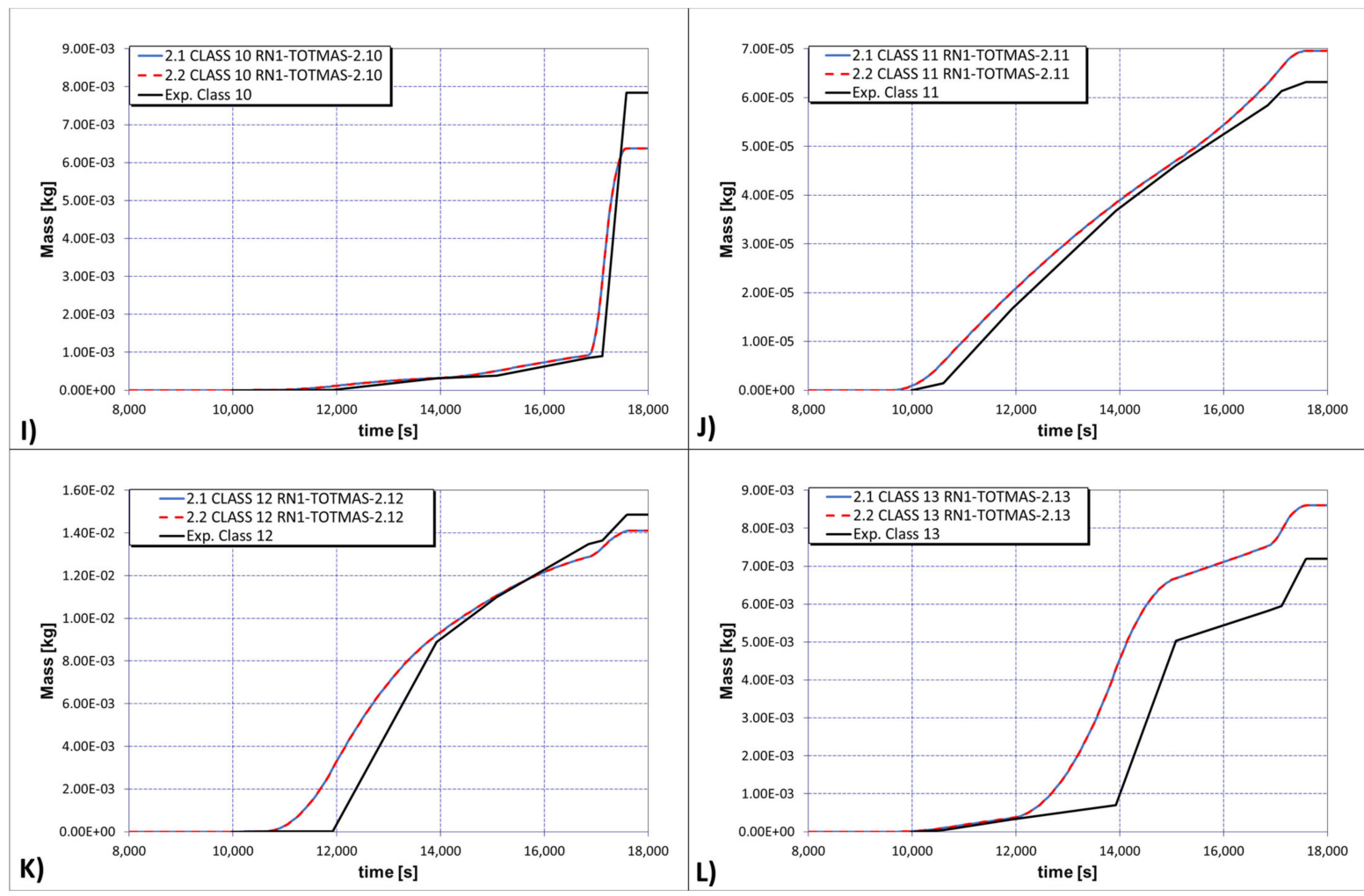

Figure 27. Comparison of classes mass between the experiment and MELCOR (upper plenum).

Table 8 shows the total amount of RNs in Point C (hot leg). Because these data were imposed as a boundary conditions, the results for both versions of the code are almost identical.

Table 8. Comparison of total classes mass between experiment and MELCOR.

\begin{tabular}{ccccc}
\hline Class & Exp. $[\mathbf{k g}]$ & MELCOR 2.1 $[\mathbf{k g}]$ & MELCOR 2.2 $[\mathbf{k g}]$ & MELCOR Variable \\
\hline 1 & $3.65 \times 10^{-7}$ & $3.79 \times 10^{-7}$ & $3.79 \times 10^{-7}$ & RN1-TOTMAS-2.1 \\
2 & $9.99 \times 10^{-3}$ & $1.08 \times 10^{-2}$ & $1.08 \times 10^{-2}$ & RN1-TOTMAS-2.2 \\
3 & $3.55 \times 10^{-4}$ & $3.97 \times 10^{-4}$ & $3.97 \times 10^{-4}$ & RN1-TOTMAS-2.3 \\
4 & $8.69 \times 10^{-4}$ & $9.06 \times 10^{-4}$ & $9.06 \times 10^{-4}$ & RN1-TOTMAS-2.4 \\
5 & $3.23 \times 10^{-4}$ & $3.44 \times 10^{-4}$ & $3.44 \times 10^{-4}$ & RN1-TOTMAS-2.5 \\
6 & $1.09 \times 10^{-2}$ & $1.19 \times 10^{-2}$ & $1.19 \times 10^{-2}$ & RN1-TOTMAS-2.6 \\
7 & $8.31 \times 10^{-3}$ & $9.32 \times 10^{-3}$ & $9.32 \times 10^{-3}$ & RN1-TOTMAS-2.7 \\
8 & $1.73 \times 10^{-5}$ & $2.12 \times 10^{-5}$ & $2.12 \times 10^{-5}$ & RN1-TOTMAS-2.8 \\
10 & $7.84 \times 10^{-3}$ & $6.38 \times 10^{-3}$ & $6.38 \times 10^{-3}$ & RN1-TOTMAS-2.10 \\
11 & $6.32 \times 10^{-5}$ & $6.96 \times 10^{-5}$ & $6.96 \times 10^{-5}$ & RN1-TOTMAS-2.11 \\
12 & $1.49 \times 10^{-2}$ & $1.41 \times 10^{-2}$ & $1.41 \times 10^{-2}$ & RN1-TOTMAS-2.12 \\
13 & $7.19 \times 10^{-3}$ & $8.60 \times 10^{-3}$ & $8.60 \times 10^{-3}$ & RN1-TOTMAS-2.13 \\
TOTAL & $\mathbf{6 . 0 8} \times \mathbf{1 0}-\mathbf{2}$ & $\mathbf{6 . 2 8} \times \mathbf{1 0}^{-\mathbf{2}}$ & $\mathbf{6 . 2 8} \times \mathbf{1 0 ^ { - 2 }}$ & \\
\hline
\end{tabular}

Comparing classes from both models AC and NAC (Tables 5 and 8), it is possible to detect some differences; for instance, it is interesting that for the model AC for the MELCOR 2.2 the Class 1 was zero underlining the complete transport of the FP gasses into the containment vessel. In addition, this phenomenon is showed in Table 8, where both MELCOR 2.1 and MELCOR 2.2 have 10\% more Class 1 mass in comparison to the experimental results. Equivalently, for both code versions, the results on the Class 13 were zero in AC model underling a similar behaviour to the Class 1 . Due to the lack of measurement sensibility, the Class 9 was not detected in the experiment, however MELCOR 2.1 and 2.2 were able to simulate a small quantity of those elements. 


\subsubsection{Fission Product Element Injected into the Containment}

As it was reported in Section 6.1.5, the total mass of steam, hydrogen and radionuclides released into the containment in the experiment was compared with the results in MELCOR, in the Table 9. It shows the masses divided by classes were comparable with the experimental values and the MELCOR results. Class 11 (uranium) showed less difference compared with the results. It is interesting to observe that this particular class had the largest difference with the experimental results in the model with the active channel. The total amount of mass injected into the containment is in the same order of magnitude as the MELCOR results with the model without including the active channel with an error of around $35 \%$.

Table 9. Material injected into the containment vessel during the transient.

\begin{tabular}{|c|c|c|c|c|c|}
\hline \multirow{2}{*}{ Class } & \multirow{2}{*}{$\begin{array}{c}\text { Experiment } \\
{[\mathrm{kg}]}\end{array}$} & \multirow{2}{*}{$\begin{array}{c}\text { Estimated Relative } \\
\text { Uncertainty }\end{array}$} & \multicolumn{2}{|c|}{ MELCOR } & \multirow{2}{*}{$\begin{array}{c}\text { MELCOR } \\
\text { Variable }\end{array}$} \\
\hline & & & NAC * $2.1[\mathrm{~kg}]$ & $\mathrm{NAC} * 2.2[\mathrm{~kg}]$ & \\
\hline 1 & $2.740 \times 10^{-2}$ & 16.1 & $3.350 \times 10^{-7}$ & $3.370 \times 10^{-7}$ & RN1-TYCLT-1-2.4 \\
\hline 2 & $4.430 \times 10^{-3}$ & 29.5 & $9.630 \times 10^{-3}$ & $8.680 \times 10^{-3}$ & RN1-TYCLT-2-2.4 \\
\hline 3 & $8.300 \times 10^{-5}$ & 17.2 & $3.550 \times 10^{-4}$ & $3.540 \times 10^{-4}$ & RN1-TYCLT-3-2.4 \\
\hline 4 & $4.060 \times 10^{-4}$ & 17 & $9.060 \times 10^{-4}$ & $9.060 \times 10^{-4}$ & RN1-TYCLT-4-2.4 \\
\hline 5 & $1.240 \times 10^{-4}$ & 17 & $3.040 \times 10^{-4}$ & $3.030 \times 10^{-4}$ & RN1-TYCLT-5-2.4 \\
\hline 6 & $1.270 \times 10^{-3}$ & 19.9 & $1.070 \times 10^{-2}$ & $1.060 \times 10^{-2}$ & RN1-TYCLT-6-2.4 \\
\hline 7 & $4.160 \times 10^{-3}$ & 18.01 & $8.310 \times 10^{-3}$ & $8.290 \times 10^{-3}$ & RN1-TYCLT-7-2.4 \\
\hline 8 & $5.570 \times 10^{-5}$ & 23 & $1.890 \times 10^{-5}$ & $1.880 \times 10^{-5}$ & RN1-TYCLT-8-2.4 \\
\hline 9 & $1.490 \times 10^{-6}$ & 29.64 & 0.000 & 0.000 & RN1-TYCLT-9-2.4 \\
\hline 10 & $6.500 \times 10^{-5}$ & 17 & $5.680 \times 10^{-3}$ & $5.690 \times 10^{-3}$ & RN1-TYCLT-10-2.4 \\
\hline 11 & $4.200 \times 10^{-5}$ & 21.57 & $6.120 \times 10^{-5}$ & $6.190 \times 10^{-5}$ & RN1-TYCLT-11-2.4 \\
\hline 12 & $1.650 \times 10^{-3}$ & 20 & $1.250 \times 10^{-2}$ & $1.260 \times 10^{-2}$ & RN1-TYCLT-12-2.4 \\
\hline 13 & $1.350 \times 10^{-3}$ & 17 & $7.670 \times 10^{-3}$ & $7.650 \times 10^{-3}$ & RN1-TYCLT-13-2.4 \\
\hline TOTAL & $4.100 \times 10^{-2}$ & & $5.610 \times 10^{-2}$ & $5.520 \times 10^{-2}$ & \\
\hline
\end{tabular}

${ }^{*}$ NAC no active channel. ${ }^{2}$ The estimated relative uncertainty by class. It was calculated from the estimated relative uncertainty by element from Table 6 taken into account the element mass for each class.

\section{Discussion and Conclusions}

In this paper, the bundle degradation, oxidation, and fission products release transport phenomena are analysed using the FPT3 experiment pointing out the model development based on the benchmarking activity code-to-code and code-to-data. In particular, the analysis purpose focuses on models assessment with particular attention on the influence of $\mathrm{B}_{4} \mathrm{C}$ oxidation on the release and transport of FPs. Such phenomena represent concern point in the nuclear industry, as was highlighted during the Fukushima Daiichi accident. Indeed, the simulation of the source term is a key point to evaluate the severe accident hazard along with other safety aspects

The result analyses highlight the MELCOR 2.2 capabilities and discrepancies in comparison with MELCOR 2.1 and the FPT3 experimental data. The general trend of the main phenomena is predicted from both codes with some differences in timing and releases amounts during the degradation phase. A particular attention was given to the boron carbide-steam reactions which influenced the:

- The hydrogen production;

- Production of boric compounds was capable to influence the fuel and internal structures material relocation behaviour and to influence the fission products transport in the primary circuit;

- Influence the iodine behaviour in the containment vessel in particular during the washing phase.

The MELCOR 2.1 and 2.2 codes are able to simulate the iodine speciation with particular attention on the influence of the control rod chemistry. 
As final remarks, the limitations of MELCOR 2.1 and MELCOR 2.2 to simulate the detailed phenomena in chemistry, physics and thermohydraulic with simplified models are compensated by the code's adaptability in using same components with different models. For example, the CV module is linked to the RN model leading FP releases and their transport. However, the comparison with the data shows some divergences highlighted, as sequence phenomelogical time, the release masses, and the steam condensation.

For these reasons, future work will focus on improving the model and preparing a large spectrum of analyses in order to understand their influences.

Author Contributions: A.F.yF.: conceptualization Section 5.2. Data curation, writing-original draft preparation, model development, calculation analysis, visualisation, investigation, and validation. G.M.: Conceptualisation Section 5.1. Methodology, supervision writing-reviewing and editing, validation. D.F.: writing —original draft preparation, writing-review and editing, visualisation. T.M.: Writing - review and editing, visualisation, technical support, language and grammar spelling. All authors have read and agreed to the published version of the manuscript.

Funding: This research received no external funding.

Institutional Review Board Statement: Not applicable.

Informed Consent Statement: Not applicable.

Data Availability Statement: These results are part of an institutional report, the data published in this paper is the only public information available.

Conflicts of Interest: The authors declare no conflict of interest.

\section{References}

1. Kim, S.; Kim, S. Impact of the Fukushima Nuclear Accident on Belief in Rumors: The Role of Risk Perception and Communication. Sustainbility 2017, 9, 2188. [CrossRef]

2. Okubo, T.; Narita, D.; Rehdanz, K.; Schroeder, C. Preferences for Nuclear Power in Post-Fukushima Japan: Evidence from a Large Nationwide Household Survey. Energies 2020, 13, 2938. [CrossRef]

3. Corey, G.R. A Brief Review of the Accident at Three Mile Island. IAEA Bull. 1979, 21, 54-59.

4. INSAG; IAEA. The Chernobyl Accident: Updating of INSAG-1; INSAG Series; International Atomic Energy Agency-IAEA: Vienna, Austria, 1992; ISBN 9201046928.

5. The Fukushima Daiichi Accident; Non-Serial Publications; International Atomic Energy Agency-IAEA: Vienna, Austria, 2015; ISBN 9789201070159.

6. IRSN Web Page. Available online: https://www.irsn.fr/EN/Research/Research-organisation/Research-programmes /PHEBUSPF/Pages/Severe-accident-research-programme-PHEBUS-FP-3455.aspx (accessed on 17 May 2021).

7. Haste, T. Specification of International Standard Problem ISP-46 (Phebus FPT1), Revision 0; IPSN Note Technique: Cadarache, France, 2001.

8. der Hardt, P.; Jones, A.V.; Lecomte, C.; Tattegrain, A. Nuclear safety research: The phebus FP severe accident experimental program. Nucl. Saf. 1994, 35, 187-205.

9. Humphries, L.L.; Cole, R.K.; Louie, D.L.; Figueroa, V.G.; Young, M.F.; Esmaili, H. MELCOR Computer Code Manuals Vol. 1: Primer and Users' Guide; Version 2.1.6840; SAND2015-6691 R; Sandia National Laboratories: Washington, DC, USA, 2015.

10. Humphries, L.L.; Cole, R.K.; Louie, D.L.; Figueroa, V.G.; Young, M.F. MELCOR Computer Code Manuals. Vol. 2: Reference Manual; Version 2.1.6840; SAND2015-6691 R; Sandia National Laboratories: Washington, DC, USA, 2015.

11. Humphries, L.L.; Beeny, B.A.; Gelbard, F.; Louie, D.L.; Phillips, J. MELCOR Computer Code Manuals. Vol. 1: Primer and Users' Guide; Version 2.2.9541; Sandia National Laboratories: Washington, DC, USA, 2017; Volume 1.

12. Humphries, L.L.; Cole, R.K.; Louie, D.L.; Figueroa, V.G.; Young, M.F. MELCOR Computer Code Manuals. Vol. 2: Reference Manual; Version 2.2.9541; Sandia National Laboratories: Washington, DC, USA, 2017.

13. Bieliauskas, A.H.T. Specification of SARNET2 PHEBUS FPT3 Benchmark; DPAM-SEMIC-2011-057, Technical note; IRSN: Fontenayaux-Roses, France, 2011.

14. Di Giuli, M.; Haste, T.; Biehler, R.; Bosland, L.; Herranz, L.E.; Fontanet, J.; Beuzet, E.; Torkhani, M.; Davidovich, N.; Klein-Hessling, W.; et al. SARNET benchmark on Phébus FPT3 integral experiment on core degradation and fission product behaviour. Ann. Nucl. Energy 2016, 93, 65-82. [CrossRef]

15. Mazzini, G. Severe Accident Phenomenology Analyses and Fission Gas Release in Advanced Nuclear Reactors. Ph.D. Thesis, University of Pisa, Pisa, Italy, 2012.

16. Gonfiotti, B.; Paci, S. Stand-alone containment analysis of the Phébus FPT-3 test with the ASTEC and the MELCOR codes. In Proceedings of the 26th International Conference on Nuclear Engineering, London, UK, 22-26 July 2018; American Society of Mechanical Engineers: Washington, DC, USA, 2018. 
17. Jacquemain, D.; Bourdon, S.; de Braemaeker, A.; Barrachin, M. FPT1 Final Report (Final Version); Institut de protection et de sureté nucléaire: Cadarache, France, 2000.

18. Grégoire, A.-C.; March, P.; Payot, F.; Ritter, G.; Zabiégo, M.; Bremaecker, A.; Biard, B.; Grégoire, G.; Schlutig, S. Phebus FP—FPT2 Final Report; IRSN: EU, 2008.

19. Gonfiotti, B.; Paci, S. Stand-alone containment analysis of Phébus FPT tests with ASTEC and MELCOR codes: The FPT-2 test. Heliyon 2018, 4, e00553. [CrossRef] [PubMed]

20. Gauntt, R.O. MELCOR Computer Code Manuals—Reference Manual; Version 2.0; U.S. Nuclear Regulatory Research: Washington, DC, USA, 2008.

21. Humphries, L.L.; Beeny, B.A.; Faucett, C.; Gelbard, F.; Haskin, T.; Louie, D.L.; Phillips, J. MELCOR Computer Code Manuals. Vol. 2: Reference Manual; Version 2.2.14959; NRC: Albuquerque, NM, USA, 2019.

22. Galushin, S.; Kudinov, P. Analysis of the Effect of Severe Accident Scenario on Debris Properties in Lower Plenum of Nordic BWR Using Different Versions of MELCOR Code. Sci. Technol. Nucl. Install. 2019, 2019, 5310808. [CrossRef]

23. OECD-NEA Project: Thermodynamic Characterisation of Fuel Debris and Fission Products Based on Scenario Analysis of Severe Accident Progression at Fukushima Daiichi Nuclear Power Station (TCOFF). Available online: https://www.oecd-nea.org/jcms/ pl_25584/thermodynamic-characterisation-of-fuel-debris-and-fission-products-based-on-scenario-analysis-of-severe-accidentprogression-at-fukushima-daiichi-nuclear-power-station-tcoff (accessed on 1 April 2021).

24. OECD-NEA Project: Preparatory Study on Analysis of Fuel Debris (PreADES) Project. Available online: https://www.oecd-nea. org/jcms/pl_25169/preparatory-study-on-analysis-of-fuel-debris-preades-project (accessed on 1 April 2021).

25. Payot, F.; Haste, T.; Biard, B.; Bot-Robin, F.; Devoy, J.; Garnier, Y.; Guillot, J.; March, P. PHEBUS FP FPT3 Final Report; Institut de protection et de sureté nucléaire: Cadarache, France, 2010. 